UNIVERSIDADE DE BRASÍLIA

Faculdade de Agronomia e Medicina Veterinária

Programa de Pós-graduação em Saúde Animal

\title{
PREVALÊNCIA E FATORES DE RISCO DA TUBERCULOSE BOVINA NO ESTADO DE SANTA CATARINA
}

FLÁVIO PEREIRA VELOSO

DISSERTAÇÃO DE MESTRADO

EM SAÚDE ANIMAL

BRASÍLIA/DF

DEZEMBRO/ 2014 
Faculdade de Agronomia e Medicina Veterinária

Programa de Pós-Graduação em Saúde Animal

\title{
PREVALÊNCIA E FATORES DE RISCO DA TUBERCULOSE BOVINA NO ESTADO DE SANTA CATARINA
}

\author{
FLÁVIO PEREIRA VELOSO
}

ORIENTADOR: PROF. DR. VÍTOR SALVADOR PICÃO GONÇALVES

\author{
PUBLICAÇÃO № 103/2014
}

DISSERTAÇÃO DE MESTRADO EM SAÚDE ANIMAL

ÁREA DE CONCENTRAÇÃO: MEDICINA PREVENTIVA E PATOLOGIA VETERINÁRIA LINHA DE PESQUISA: EPIDEMIOLOGIA, PREVENÇÃO E CONTROLE DE DOENÇAS DOS ANIMAIS E GESTÃO DOS RISCOS PARA A SAÚDE PÚBLICA

\author{
BRASÍLIA/DF \\ DEZEMBRO/ 2014
}


UNIVERSIDADE DE BRASÍLIA

PREVALÊNCIA E FATORES DE RISCO DA TUBERCULOSE BOVINA NO ESTADO DE SANTA CATARINA

FLÁVIO PEREIRA VELOSO

DISSERTAÇ̃̃O DE MESTRADO SUBMETIDA AO PROGRAMA DE PÓS- GRADUAÇÃO EM SAÚDE ANIMAL, COMO PARTE DOS REQUISITOS NECESSÁRIOS A OBTENÇÃO DO GRAU DE MESTRE EM SAÚDE ANIMAL.

APROVADA POR:

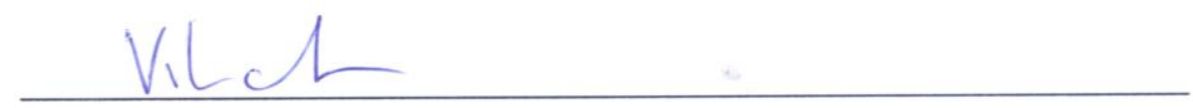

VÍTOR SALVגDOR PICÃO GONÇALVES, Doutor (UnB). Orientador.

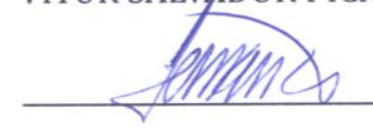

FERNANDO FERREIRA, Doutor (FMVZ/USP).

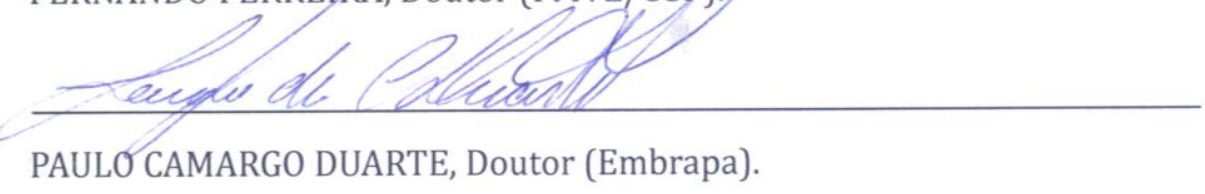

BRASÍLIA/DF, 01 DE DEZEMBRO DE 2014 


\section{REFERÊNCIA BIBLIOGRÁFICA E CATALOGAÇÃO}

VELOSO, F.P. Prevalência e fatores de risco da tuberculose bovina no Estado de Santa Catarina. Brasília: Faculdade de Agronomia e Medicina Veterinária, Universidade de Brasília, 2014, 31p. Dissertação de Mestrado.

Documento formal, autorizando reprodução desta dissertação de Mestrado para empréstimo ou comercialização, exclusivamente para fins acadêmicos; foi passado pelo autor à Universidade de Brasília e acha-se arquivado na secretaria do Programa. 0 autor reserva para si os outros direitos autorais, de publicação. Nenhuma parte desta dissertação de mestrado pode ser reproduzida sem a autorização por escrito do autor. Citações são estimuladas, desde que citada a fonte.

Veloso, Flávio Pereira

Prevalência e fatores de risco da tuberculose bovina no Estado de Santa Catarina / Flávio Pereira Veloso

Orientação de Vítor Salvador Picão Gonçalves.

Brasília, 2014. 31p.: il.

Dissertação de mestrado (M) - Universidade de Brasília / Faculdade de Agronomia e Medicina Veterinária, 2014.

1. Tuberculose bovina. 2. Prevalência. 3. Fatores de risco. 4. Santa Catarina. I. VELOSO, F.P. II. Título

Agris / FAO 
"To understand God's thoughts we must study statistics, for these are the measure of His purpose."

(Florence Nightingale) 


\section{AGRADECIMENTOS}

Aos deuses e à graça, por eles a mim concedida, de poder realizar este sonho;

Aos meus pais: Celso R. V. Velloso, também um colega médico veterinário, e Maria da Graça Pereira - responsáveis pela minha formação pessoal, meus princípios, valores e ensinamentos e pela estrutura fundamental para minha trajetória acadêmica e profissional, em particular a realização deste sonho;

Aos irmãos Henrique, Ricardo, Gabi, Marcelle, Ly e Canaan e sobrinhos, Bê, Lulu, Mel e o Nenem que está por vir, pelo apoio permanente e, acima de tudo, por existirem em minha vida.

À minha vozinha Dinah, pelo carinho, presença e apoio em todos os momentos da minha vida; a todos os meus tios e primos, pelo carinho e torcida.

Ao meu Orientador, Prof. Vitor, por quem cultivo grande admiração e inspiração: pelos ensinamentos e experiência, apoio e paciência; igualmente, à Ana Lourdes, uma grande professora, a quem atribuo parte importante do meu aprendizado, e ao Prof. Mauro;

Um agradecimento e um reconhecimento muito destacados a todos os meus colegas dos escritórios locais e regionais da CIDASC, os grandes responsáveis pela consecução do presente trabalho: profissionais dedicados, batalhadores, guerreiros.

Aos amigos e colegas da GEDSA, na CIDASC, em especial à Karina, grande responsável pela idealização deste estudo; ao Diretor João Marques e ao Presidente Enori Barbieri, por todo o apoio nesta empreitada;

Aos professores da FMVZ/USP: Prof. Fernando e Prof. José Soares, também pelos ensinamentos e pelo apoio fornecidos;

Aos amigos e colegas do laboratório: Bidiah, Geórgia, Marina, Geraldinho, Catia e Silene;

Um agradecimento muito especial ao Christian e a toda a sua família, por me acolherem sempre, carinhosamente, aqui em Brasília; ao Cláudio e ao Felipe, amigos conquistados durante o mestrado, companheiros de prosa, de angústias e de algumas cervejas providenciais;

Aos meus amigos eternos - os de sempre: Valter, Marcos, Felipe, André e Igor; e aos conquistados aqui em Brasília, que levarei, sempre, em meu pensamento;

A todos os professores que marcaram minha vida acadêmica, em especial Prof. Marcelo e Profa. Silvana, meus orientadores durante a graduação, e aos professores dos Programas de Pós-Graduação em Saúde Animal, em Saúde Coletiva e em Medicina Tropical da UnB, pelos valorosos conhecimentos adquiridos.

Ao Nero, meu cão, de quem me separei ao vir para Brasília e hoje me acompanha lá do céu. Aos meus vizinhos Diogo e Priscila, Herbert e Kellen e Alessandro, por cuidarem tão dedicadamente do Nero e tomarem conta da minha casa durante a minha ausência.

Ao Clube Atlético Mineiro, por todas as emoções, sofrimentos e alegrias proporcionados ao longo de toda uma vida - e cujo excesso, nos últimos dois anos, quase não me permitiu completar a presente jornada. 


\section{SUMÁRIO}

Página

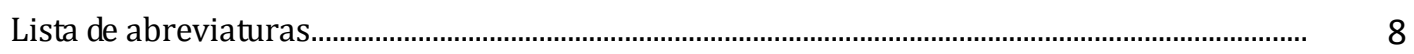

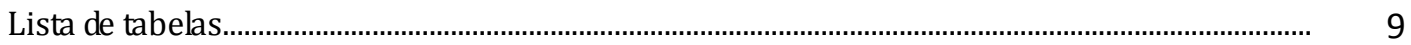

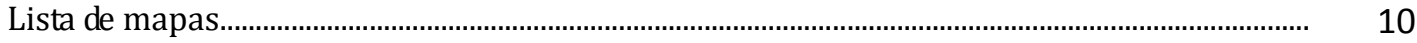

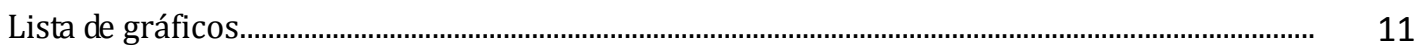

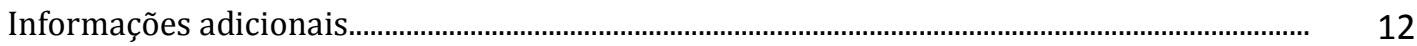

\section{CAPÍTULO I}

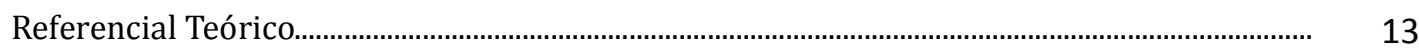

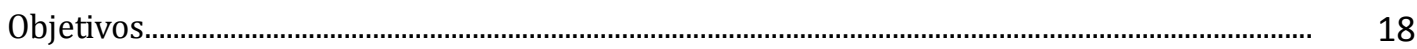

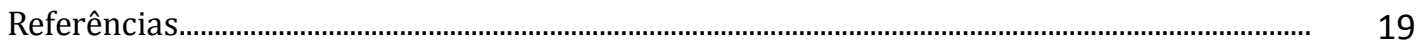

\section{CAPÍTULO II}

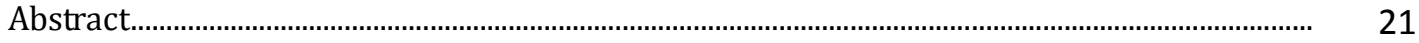

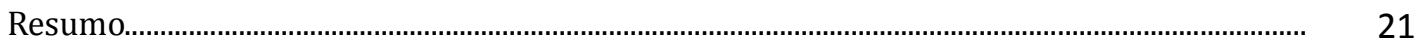

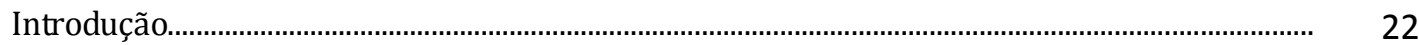

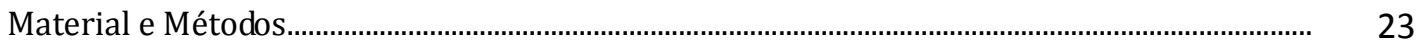

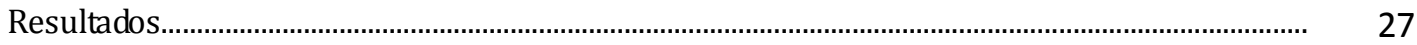

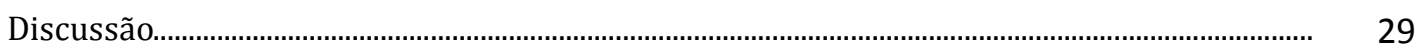

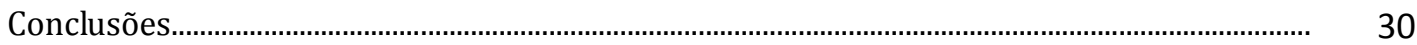

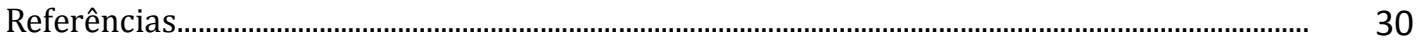




\section{LISTA DE ABREVIATURAS}

AUC

BCG

CD

CIDASC

DTH

HIV

IBGE

IFN- $\gamma$

IgG

MAPA

M. avium

M. bovis

M. tuberculosis

OIE

PCR

PNCEBT

PPD

ROC

SC

TB

Th

TCC

VPP
Area Under the Curve

Bacillus Calmette-Gérin

Grupamento de diferenciação (cluster of differentiation): sistema de classificação de proteínas presentes na superfície celular

Companhia Integrada de Desenvolvimento Agrícola de Santa Catarina

Hipersensibilidade do tipo retardada (delayed type hypersensitivity)

Vírus da imunodeficiência humana (Human Immunodeficiency Virus)

Instituto Brasileiro de Geografia e Estatística

Interferon-gama

Imunoglobulina $\mathrm{G}$

Ministério da Agricultura Pecuária e Abastecimento

Mycobacterium avium

Mycobacterium bovis

Mycobacterium tuberculosis

Organização Mundial de Saúde Animal

Reação em cadeia da polimerase (polymerase chain reaction)

Programa Nacional de Controle e Erradicação da Brucelose e Tuberculose

Derivado proteico purificado (purified protein derivative)

Receiver Operating Characteristic

Santa Catarina

Tuberculose Bovina

Linfócito T auxiliar (helper)

Teste cervical comparativo

Valor Preditivo Positivo 


\section{LISTA DE TABELAS}

Página

Quadro 1. Dados censitários da população bovina do estado de Santa Catarina em 2012, segundo a região produtora.

Quadro 2. Prevalência de propriedades positivas para tuberculose em Santa Catarina por Região.

Quadro 3. Prevalência de fêmeas em idade reprodutiva (igual ou superior a 24 meses) positivas para tuberculose em Santa Catarina por região.

Quadro 4. Variáveis com valor-p $\leq 20$ analisadas quanto à associação com a ocorrência de tuberculose no rebanho catarinense, número de casos e controles em cada categoria e pvalor..

Quadro 5. Modelo de regressão logística no formato model-based (Hosmer, Lemeshow \& Sturdivant 2013)

Quadro 6. Modelo de regressão logística, formato design-based (Hosmer, Lemeshow \& Sturdivant 2013), considerando os pesos amostrais das propriedades em cada região....... 


\section{LISTA DE MAPAS}

Página

Mapa 1. Divisão do Estado de Santa Catarina em regiões, segundo a característica produtiva e de comercialização.

Mapa 2. Propriedades positivas para tuberculose no inquérito epidemiológico executado em Santa Catarina, 2012 - 2013 


\section{LISTA DE GRÁFICOS}

Página

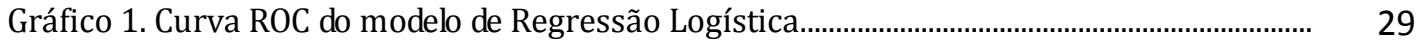




\section{INFORMAÇÕES ADICIONAIS}

A presente dissertação encontra-se formatada segundo as normas do sistema de submissão de artigos para publicação na revista Pesquisa Veterinária Brasileira (PVB). 0 Capítulo I inclui o referencial teórico do trabalho de pesquisa, assim como os seus objetivos. O Capítulo II descreve a metodologia e resultados da pesquisa realizada e está escrito na forma de artigo completo para publicação em periódico científico com JCR, classificado como B1 ou A2 no sistema Qualis/CAPES. 


\section{CAPÍTULO I}

\section{REFERENCIAL TEÓRICO}

\section{Etiopatogenia}

A tuberculose é causada por bacilos ácido-álcool resistentes, gram-positivos, não esporogênicos. Os agentes etiológicos da doença, em mamíferos, são Mycobacterium tuberculosis, M. bovis, M. africanum e M. microti. O M. tuberculosis é o principal causador da tuberculose em humanos e em outros primatas; na África Tropical, o $M$. africanum também causa tuberculose humana. $0 \mathrm{M}$. bovis provoca a tuberculose bovina e é o principal responsável pela forma zoonótica da doença. 0 M. microti acomete roedores, mas não apresenta interesse zoonótico (Acha \& Szyfres 2003).

A tuberculose humana causada pelo Mycobacterium tuberculosis é uma das doenças infecciosas mais amplamente difundidas no mundo e a principal causa de morte entre adultos, atribuída a um único agente infeccioso. A tuberculose bovina, causada pelo $M$. bovis, é uma importante zoonose, que pode se espalhar entre humanos por meio da inalação de gotículas infecciosas ou pela ingestão do leite cru. A proporção de casos de tuberculose humana provocada pelo M. bovis é mal conhecida (Cosivi et al 1998, Thoen, LoBue \& Kantor 2006).

Em bovinos, a via de infecção da tuberculose é, geralmente, broncogênica. Animais com boas condições imunológicas podem debelar a infecção ainda na sua fase inicial; contudo, a doença pode progredir e se espalhar no organismo por três mecanismos: via linfática, com acometimento secundário dos linfonodos mediastinais, cuja associação com a lesão no tecido pulmonar constitui o complexo primário; pelo exsudato presente nas vias aéreas, rico em bacilos; ou pela via hematógena, por meio de êmbolos sépticos que se disseminam rapidamente pelo sangue, podendo afetar qualquer órgão, caracterizando o quadro miliar da doença. Como o micro-organismo se replica lentamente no interior dos macrófagos, as lesões da tuberculose invariavelmente assumem característica de cronicidade (Santos \& Guedes 2010).

O macrófago é a principal célula no controle das infecções micobacterianas, e o linfócito T (célula-T) o maior indutor de proteção adquirida (Buddle et al 2002a). As células-T auxiliares (Th-1) são de particular importância na defesa contra patógenos intracelulares (Pollock, Welsh \& McNair 2005). Quando um animal é infectado pelas micobactérias tuberculosas, os antígenos micobacterianos induzem a memória celular mediada pela Th-1, o que constitui a base da resposta ao diagnóstico por meio do teste de tuberculinização (Tizard 2009). A imunidade celular é caracterizada pela expressiva produção de interferon-gama (IFN- $\gamma$ ), essencial para a estimulação da atividade microbicida dos macrófagos. Em bovinos infectados pelo M. bovis, o CD4 parece ser o maior produtor de IFN- $\gamma$; células $\gamma \delta$ também são potenciais fontes desta citocina, porém em menor escala (Pollock, Welsh \& McNair 2005).

\section{Fatores de risco}

Na transmissão da tuberculose bovina, as interações entre hospedeiro, patógeno e ambiente são de elevada complexidade, podendo não ser possível predizer todos os fatores particulares de risco relacionados à sua disseminação entre rebanhos. A densidade animal é considerada um fator primário, já que eleva a probabilidade de transmissão via aerossóis (Skuce, Allen \& McDowell 2012). Animais com alterações patológicas mais extensas apresentam maior probabilidade de secretar o $M$. bovis pelo muco nasal, constituindo uma ameaça maior de infecção para outros animais (Pollock, Welsh \& McNair 2005).

Skuce, Allen \& McDowell (2012) mencionam como fatores de risco de transmissão da tuberculose bovina entre os rebanhos: histórico de incidência da doença; movimentação animal; ocorrência da doença em terrenos contíguos à propriedade; tamanho e tipo do rebanho; tipo de instalação; aquisição de animais a partir de rebanhos com histórico de tuberculose; fornecimento de alimento no interior de instalações; e, em algumas localidades, densidade ou atividade de espécies silvestres.

No Brasil, os estudos de prevalência e fatores de risco conduzidos em Minas Gerais (Belchior 2000), Paraná (Silva 2012), Bahia (Costa 2012) e Mato Grosso (Néspoli 2012) identificaram como fatores de risco a produção leiteira, em geral associada a rebanhos maiores e com maior grau de tecnificação. As prevalências estimadas nos respectivos Estados foram de 5,02\%, 2,15\%, 1,6\% e 1,3\% de rebanhos infectados, e 0,8\%, 0,42\%, 0,21\% e 0,123\% de bovinos adultos positivos para tuberculose (Belchior 2000, Silva 2012, Néspoli 2012, Costa 2012). Segundo Belchior (2000), a probabilidade de infeção aumenta nas propriedades de produção mais intensiva e tecnificada, o que pode estar relacionado a sistemas de criação animal em confinamento parcial ou total.

\section{Fauna Silvestre de vida livre}

Em diversos países cuja prevalência da doença foi substancialmente reduzida, a erradicação vem sendo dificultada em decorrência da presença de reservatórios silvestres (Thoen, LoBue \& Kantor 2006). É o caso da presença de cervídeos, na América do Norte; texugos (Meles meles), na Grã-Bretanha; porcos selvagens, em variadas regiões da Europa; gambás (Trichosurus vulpecula), na Nova Zelândia; e búfalos (Syncerus caffer), na África do Sul (Fitzgerald \& Kaneene 2012). 
No Canadá, acredita-se que a tuberculose bovina em animais de vida silvestre ocorra apenas em bisões presentes em um parque nacional localizado na província de Alberta. Um esforço nacional foi adotado para lidar com este problema, tendo sido considerada, entre outras medidas, sua depopulação. Nos Estados Unidos, a tuberculose causada por M. bovis em cervídeos foi identificada no início da década de 1990 (Essey \& Koller 1994).

Porcos selvagens encontram-se amplamente distribuídos na Eurásia e na África e são altamente susceptíveis à tuberculose bovina. Em algumas regiões da Espanha, Portugal, Itália e na ilha mediterrânea da Córsega Francesa, o crescimento da concentração de porcos selvagens e de javalis foi correlacionado com a ocorrência da tuberculose em bovinos, caprinos, suínos domésticos e cervídeos. Estes suídeos são utilizados como sentinelas nos estudos para detecção da contaminação ambiental nas ilhas havaianas e na Nova Zelândia (Fitzgerald \& Kaneene 2012).

Na África, a tuberculose bovina foi introduzida no século 19, aparentemente por meio de rebanhos bovinos domésticos transportados por colonizadores britânicos, e, em seguida, difundiu-se para várias espécies selvagens. Búfalos residentes no Parque Nacional de Kruger, na África do Sul, são particularmente acometidos pela tuberculose, de forma endêmica. No mesmo Parque, outras espécies silvestres também são acometidas pelo $M$. bovis, entre as quais leões (Panthera leo), chitas (Acinonyx jubatus), babuínos (Papio ursinus), cudo (Tragelaphus strepsiceros), leopardos (Panthera pardus), hienas (Crocuta crocuta), genetas (Genetta tigrina), javalis (Phacochoerus aethiopicus), porcos selvagens (Potamochoerus porcus) e antílopes (Taurotragus Oryx). No entanto, com a possível exceção do cudo, todas as demais espécies parecem ser hospedeiros secundários terminais do agente (Fitzgerald \& Kaneene 2012).

Munyeme et al (2009) relataram uma ocorrência expressivamente mais alta da tuberculose bovina nas áreas de interface com animais silvestres na Zâmbia. Os dados indicaram a existência de focos concêntricos de infecção no entorno do santuário selvagem de Kafue Basin. Nas regiões de Lochinvar e Blue Lagoon, ambas de interface com a fauna silvestre, a prevalência também foi mais alta do que no distrito de Kazungula, que não apresenta esta interface.

É importante destacar que, apesar de diversas localidades mundiais terem identificado espécies silvestres como potenciais reservatórios da tuberculose, seu grande impacto na manutenção da doença entre rebanhos bovinos só foi relatado, de fato, na Nova Zelândia e nas ilhas britânicas, cujos programas de erradicação da doença vêm sendo fortemente prejudicados em decorrência do contato entre esta fauna e os animais domésticos.

Em áreas de risco da Nova Zelândia, gambás (Trichosurus vulpecula) e cervos silvestres constituem reservatórios do M. bovis. Estratégias de controle da população de gambás resultaram em uma drástica queda na incidência da doença em rebanhos bovinos e de cervos de produção, mas os cervos silvestres são capazes de iniciar novos focos ou reiniciá-los após a remoção dos gambás. A proximidade das fazendas a parques e florestas está associada ao número de casos positivos para a doença por ano (Ryan et al 2006, Porphyre, Stevenson \& McKenzie 2008). Naquele país, a vigilância estratégica dos animais silvestres é essencial para a detecção precoce da doença e delimitação dos focos, com o intuito de evitar sua difusão (Ryan et al 2006).

Griffin et al (1993) identificaram a presença de texugos (Meles meles) como fator de risco para tuberculose bovina em um estudo conduzido na Irlanda. Os autores recomendam cautela na interpretação desta informação, já que, possivelmente, proprietários de rebanhos infectados tenham maior percepção sobre a presença deste mustelídeo na área de sua propriedade. Ainda, alertam para o fato de que, em seus estudos, a simples presença de texugos na propriedade pressupôs a presença de texugos tuberculosos, o que pode não ser totalmente válido.

No Reino Unido, os achados de Reilly \& Courtenay (2007) reforçam as evidências do importante papel desempenhado pelos texugos (Meles meles) na manutenção da tuberculose bovina em áreas de foco. Os mustelídeos são conhecidos por provocarem danos às culturas de milho e por invadirem os galpões de ração e silagem destinadas ao gado, atraídos pelos alimentos destinados aos bovinos. Quando infectados pelo M. bovis, eliminam o agente pela urina, fezes ou expectoração, contaminando os alimentos e o ambiente, o que constitui uma provável via de transmissão aos rebanhos.

Skuce, Allen \& McDowell (2012) indicam a adoção de medidas de biossegurança abrangentes para reduzir o contato dos rebanhos bovinos com espécies silvestres, embora pouco se saiba sobre quais medidas práticas poderiam ser adotadas pelos produtores. Os estudos e as análises dos dados sugerem não haver uma solução universal para a gestão dos riscos de introdução da doença nos rebanhos. A movimentação dos bovinos deve ser feita com cautela, de modo a minimizar o contato com outros rebanhos e com a fauna silvestre, e as práticas de arraçoamento também requerem atenção, bem como as instalações utilizadas.

No Brasil, são poucos os relatos sobre o papel dos animais silvestres como reservatórios da tuberculose bovina. De fato, Abrahão (1999) destaca que até 1983 não havia nenhum registro no país. Mais recentemente, os estudos sobre a prevalência e fatores de risco para tuberculose bovina realizados no Paraná (Silva 2012), Bahia (Costa 2012) e Mato Grosso (Néspoli 2012), analisaram a presença de espécies silvestres de vida livre em propriedades de produção bovina como possíveis fatores de risco, porém não houve associação estatística entre este fenômeno e a ocorrência da doença. Cabe destacar, no entanto, que os estudos conduzidos no Brasil foram de tipo transversal. Os dados para análise dos possíveis fatores de risco foram obtidos por meio de questionário, com uma visita à propriedade, o que limita a investigação de fenômenos que não são constantes e não permite caracterizar a interface entre animais domésticos e silvestres. 


\section{Diagnóstico}

De acordo com Schiller et al (2010), o uso de testes diagnósticos de maior acurácia, frente a diferentes situações epidemiológicas, é preponderante para a redução dos custos de erradicação da tuberculose bovina a médio-longo prazo. Portanto, uma boa relação custo-efetividade de um teste diagnóstico não implica, genericamente, que ele seja o mais barato, mas sim que viabilize estratégias de maior impacto ao menor custo unitário possível.

Para o diagnóstico da tuberculose em bovinos, o antígeno mais amplamente utilizado é o PPD obtido de cultura de micobactérias inativadas pelo calor. O PPD apresenta problemas de especificidade, já que seus epítopos são compartilhados por várias micobactérias. A comparação entre a resposta induzida pelo PPD bovino, extraído do M. bovis, com a resposta induzida pelo PPD aviário, obtido do M. avium, permite a ampliação da especificidade tanto nos testes in vivo quanto nos in vitro (Palmers \& Waters 2006).

0 tradicional diagnóstico da tuberculose bovina consiste na mensuração comparada das respostas à inoculação intradérmica de PPD bovino e PPD aviário. A tuberculina injetada em um animal infectado é fagocidada pelas células de Langerhans, que a apresentam para células-T de memória. Células Th-1 produzem IFN- $\gamma$ ao reconhecerem o antígeno, ativando os macrófagos. Ocorre, então, uma reação de hipersensibilidade retardada ou tardia, caracterizada pelo aumento do volume e da espessura da pele e pela vermelhidão no local da inoculação (Pollock, Welsh \& McNair 2005, Tizard 2009).

Resultados falsos-negativos à tuberculinização intradérmica podem ocorrer em: (i) animais com tuberculose avançada; (ii) animais com infecção muito recente; (iii) vacas que tenham parido entre quatro e seis semanas antes do teste; (iv) animais muito velhos; e (v) animais que tenham sido testados no intervalo de uma a 10 semanas antes do novo teste. Animais com a doença clínica de Johne (paratuberculose), causada pelo Mycobacterium avium var. paratuberculosis, parecem desenvolver algum "fator bloqueador" que impede que as células-T reajam com o antígeno, provocando a ausência de reação ou anergia (Tizard 2009).

Uma alternativa ao clássico teste cutâneo baseia-se na detecção in vitro de IFN- $\gamma$. Sua atratividade consiste em abreviar a dupla necessidade de mobilização do rebanho e da mão de obra veterinária e na redução das variações entre os testes. Na América latina, estes testes demonstraram efetividade nas condições de campo, podendo complementar ou substituir os testes de tuberculinização (de Kantor \& Ritacco 1994). Na Austrália, o teste para deteç̧ão do IFN- $\gamma$ indicou uma sensibilidade de 93,6\% e uma especificidade de 96,3\%, em condições de campo. Outros estudos demonstraram uma sensibilidade na faixa de $81,8 \%$ a $100 \%$ e uma especificidade na faixa de 94\% a 100\% (Palmer \& Waters 2006).

A especificidade dos testes baseados no IFN- $\gamma$ pode ser ampliada utilizando-se os antígenos ESAT- 6 e CFP10, em detrimento do PPD bovino. Esses antígenos, obtidos de micobactérias tuberculosas, são potentes indutores de IFN- $\gamma$, com a vantagem de serem originados por genes ausentes em várias micobactérias ambientais e na cepa vacinal BCG. Porém, estes genes estão presentes em algumas micobactérias não tuberculosas, como o $M$. kansasii, M. marinun, M. leprae e M. smegmatis (Palmers \& Waters 2006).

Quase todos os tipos de testes sorológicos foram avaliados para a detecção de Imunoglobulina-G (IgG) contra o PPD bovino, sobretudo testes indiretos de imunoensaio enzimático, com especificidade comparável à da tuberculinização intradérmica. Porém, como a resposta humoral é predominantemente observada em estágios avançados da doença, tais ensaios são capazes de detectar indivíduos tuberculosos com lesões mais extensas, mas não animais com a infecção inaparente, resultando em baixa sensibilidade (de Kantor \& Ritacco 1994, Palmers \& Waters 2006). Todavia, se utilizada em conjunto com outros testes, a sorologia pode desempenhar um papel importante na deteç̧ão de animais cuja resposta celular esteja debilitada, subsidiando a identificação e remoção dos quadros mais severos da doença (Pollock, Welsh \& McNair 2005).

Em razão do baixo valor preditivo positivo (VPP), quando a prevalência da tuberculose bovina é muito baixa, a detecção de animais infectados é efetuada nos abatedouros, mais do que por via do teste periódico dos animais. Nos Estado Unidos e Austrália, a vigilância nos matadouros é o meio principal de detecção de novos casos de TB (Anônimo 1994). Esta tem sido uma estratégia bem sucedida, mas alguns aspectos devem ser realçados (Anônimo 1994, Corner 1990, Corner 1994, de Kantor et al 1987): (i) quando a prevalência é baixa, o VPP da inspeção visual é igualmente baixo (i.e. muitas lesões não são tuberculosas) e, por isso, as lesões têm que ser confirmadas por exame laboratorial; (ii) a sensibilidade da inspeção de rotina é baixa - de acordo com alguns autores varia entre $33 \%$ e $67 \%$ - o que tem sido confirmado por inspeções mais rigorosas (muitos animais têm apenas uma única lesão).

Para o diagnóstico post-mortem, Parra et al (2008) desenvolveram um teste de PCR em tempo real de alta especificidade, que não reage a outros micro-organismos causadores de linfadenite, como Streptococcus bovis, Arcanobacterium haemolyticum e Actinomyces bovis. A sensibilidade foi moderada: estimada em $61,11 \%$, quando aplicado em carcaças sem lesões visíveis, e 80,64\% em carcaças com lesões crônicas; portanto, uma média de $73,87 \%$.

\section{Saúde pública}

A tuberculose bovina é considerada um problema de saúde animal e de saúde pública. O Mycobacterium bovis é a principal causa de tuberculose nos bovinos; este agente infeccioso tem uma enorme variedade de 
hospedeiros, incluindo animais domésticos e selvagens, além do homem e outros primatas (O’Reilly \& Daborn 1995). Embora a tuberculose bovina seja universalmente considerada uma limitação para a produção de carne e leite, a implementação de programas de controle da doença só começou quando o risco para a saúde pública foi claramente estabelecido no início do século XX (Pritchard 1988). Por exemplo, nos Estados Unidos, o reconhecimento de que $25 \%$ dos casos fatais de tuberculose humana se deviam a M. bovis levou as autoridades veterinárias a iniciarem um programa de erradicação da doença nos rebanhos em 1917. Em contraste, os conceitos errôneos expressos por Koch em 1901, justificaram que no Reino Unido uma campanha idêntica fosse adiada até 1935 (Pritchard 1988).

A transmissão dos bovinos ao homem pode ocorrer através do consumo de leite e seus derivados e, com menor frequência, através do consumo de carne. A infecção pode também ocorrer por inalação ou através de lesões na pele, sendo o risco maior para os trabalhadores rurais, os empregados de frigoríficos e outros grupos que estejam em frequente contato com bovinos (ex. veterinários). Este fato contribui para que a tuberculose bovina seja um importante problema de saúde pública nos países com elevada porcentagem de população agrícola.

A prevalência de $M$. bovis na população humana é mal conhecida e, raramente, quantificada, em parte porque não existe um teste simples e de custo reduzido que permita fazer o diagnóstico diferencial em relação às estirpes do complexo M. tuberculosis (Grange 1996). No entanto, é sabido que a contribuição do M. bovis para a tuberculose humana depende de vários fatores, entre os quais a prevalência da tuberculose bovina, as condições socioeconômicas, os hábitos alimentares, a higiene alimentar e as medidas profiláticas. Denes (1981) considerou que, na Hungria, quando a prevalência da tuberculose bovina é alta e a higiene do leite inapropriada, a proporção de casos de tuberculose humana por $M$. bovis se aproxima de $10 \%$. Valores semelhantes foram detectados na Alemanha, na Turquia e na Itália, também em regiões com elevada prevalência de tuberculose bovina (Barwinek \& Taylor 1996). Na Itália, os beneficios econômicos obtidos com a redução de casos de tuberculose humana, que resultaram do controle da tuberculose bovina entre 1965 e 1978, foram estimados em 126 milhões de Liras (a preços de 1978). Durante este período, os custos de tratamento, hospitalização e perda de dias de trabalho foram estimados em 6,2 milhões de Liras (Caporale et al 1980). A importância da tuberculose bovina na saúde humana é claramente ilustrada por dados referentes à Holanda: antes da erradicação da doença (no período de 1933 a 1939), a porcentagem de tuberculose humana causada por M. bovis variava entre 9,6\% (tuberculose pulmonar) e 24,0\% (tuberculose extrapulmonar); após a erradicação (no período de 1946 a 1949), essas proporções baixaram para $1,5 \%$ e $3 \%$ respectivamente, sendo que todos os casos de tuberculose pulmonar por M. bovis foram detectados em crianças, enquanto a tuberculose extrapulmonar atingiu apenas adultos (Meyn 1953). Mais recentemente, na Austrália, onde a campanha de erradicação da tuberculose bovina foi executada com sucesso, concluiu-se que a tuberculose bovina é uma importante zoonose ocupacional, e que a transmissão por aerossóis é um importante mecanismo para infecção humana (Robinson et al 1988; Georghiou et al 1989).

Na América Latina, a informação epidemiológica sobre o impacto da tuberculose bovina na saúde humana é escassa (Ritacco \& Kantor 1992). Nos países em que o hábito de ferver o leite prevalece, ou nos quais a maior parte do leite é pasteurizado, a incidência de $M$. bovis em seres humanos é baixa, porém o problema persiste em áreas onde a prevalência de tuberculose bovina é elevada. No Peru, num estudo de 853 estirpes de bacilos da tuberculose, associados a casos de tuberculose pulmonar humana, 38 (4,45\%) foram classificados como M. bovis (Acha \& Szyfres 2003). Na Argentina, onde a prevalência de tuberculose bovina é relativamente alta, e o diagnóstico bacteriológico da tuberculose humana é realizado com frequência, a prevalência de $M$. bovis em seres humanos é mais elevada nas províncias de Buenos Aires e Santa Fé, onde se encontra a maior parte da população bovina (Barrera \& Kantor 1987). Nesta última província, um estudo feito entre 1984 e 1989 revelou que o M. bovis era responsável por 2,4 a 6,2\% dos casos de tuberculose humana, entre os quais $64 \%$ eram trabalhadores rurais ou empregados de frigoríficos (Latini et al 1990). Em resumo, apesar de ser difícil atribuir um valor monetário à saúde humana, os custos financeiros que resultam da prevenção, diagnóstico e tratamento da tuberculose humana são elevados, e a quebra de produtividade nos grupos de alto risco tem consequências econômicas e sociais importantes.

No entanto, o impacto da tuberculose bovina na saúde pública não é unânime na comunidade científica. Torgerson \& Torgerson (2009) argumentam que, antes de a técnica da pasteurização se tornar difundida, o $M$. bovis era isolado em $8 \%$ dos latões de leite no Reino Unido, proporcionando uma ampla exposição humana ao agente. Na década de $1930,40 \%$ das vacas de leite estavam infectadas, das quais $0,5 \%$ apresentavam mastite tuberculosa. Naquele período, cerca de 2.500 pessoas morriam, anualmente, de tuberculose bovina. Com a introdução da pasteurização no início da década de 1960, a incidência da tuberculose bovina em humanos declinou drasticamente. Ainda assim, importantes somas de recursos continuam sendo investidas pelo governo em programas de controle da tuberculose nos rebanhos bovinos britânicos.

De la Rua-Domenech (2005) destaca que, para a maior parte da população no Reino Unido, o risco de contrair a infecção pelo M. bovis a partir de animais é, aparentemente, muito baixo. Contudo, a tuberculose bovina continua sendo um problema sanitário animal naquela região e, em virtude do aumento da incidência anual da doença nos rebanhos, médicos e demais profissionais da área de saúde devem estar atentos à doença. Determinados segmentos da população, que se expõem ao consumo de leite não pasteurizado e a aerossóis de animais tuberculosos ou de suas carcaças, ainda se submetem a um risco significativo em relação ao M. bovis. 
Thoen, LoBue \& Kantor (2006) argumentam que, nas décadas de 1990 e 2000, os países industrializados voltaram a se preocupar com a tuberculose bovina devido a: (i) sua reemergência, decorrente do processo de imigração de pessoas oriundas de regiões onde a tuberculose bovina ainda é prevalente; (ii) sua ocorrência em pacientes reagentes ao HIV, incluindo a ascensão de cepas de $M$. bovis multirresistentes em pacientes HIV positivos hospitalizados; (iii) focos da tuberculose bovina em mamíferos silvestres e domésticos, com risco de transmissão ao homem; e (iv) transmissão, pela via aérea, da doença aos tratadores de animais e funcionários de indústrias de carne. Nos países em desenvolvimento, a situação da tuberculose bovina é ainda mais desafiadora. Os autores citam a situação de vários países africanos, em que a doença, associada às epidemias de HIV e aos elevados níveis de ocorrência nos animais, ainda constitui um importante obstáculo.

Michel, Müller \& van Helden (2010) acrescentam, ainda, que nos países em desenvolvimento, as condições para a transmissão do $M$. bovis não somente existem como permanecem inalteradas, frente à grande vulnerabilidade proporcionada pela pobreza, pelo HIV e pelo reduzido acesso aos serviços de saúde. Os autores concluem chamando a atenção para o fato de que há poucos estudos que investigam a prevalência da tuberculose zoonótica nas comunidades rurais dos países em desenvolvimento, que são mais afetados pela doença; a maior parte das informações disponíveis provém de estudos conduzidos em países industrializados.

\section{Consequências da tuberculose bovina para o setor pecuário}

A tuberculose bovina apresenta custos para a produção pecuária. Na ausência de medidas de controle da doença, as perdas mais prováveis para o fazendeiro são as seguintes:

- Índices de crescimento mais lentos e perda de peso em animais adultos. A tuberculose reduz o apetite e, na forma crônica, diminui a eficiência de conversão alimentar. Pesquisas com gado Zebu, em Madagascar, demonstraram perdas de peso de $12 \%$ em regime de engorda intensiva, e $28 \%$ em regime de pastagem (Blancou et al 1974);

- Rejeição parcial ou total da carcaça. Na França, em 1984, quando a prevalência de tuberculose bovina era apenas $0,08 \%$, a carne tuberculosa totalizou 375 toneladas (Jacquet 1986). Na Alemanha Ocidental, a rejeição de carcaças nos frigoríficos decresceu de 35\%, em 1950, para 0,25\%, em 1963 (Barwinek \& Taylor 1996);

- Redução da produção de leite. Os valores existentes na literatura são muito variáveis. Denes (1981), na Hungria, calculou que as vacas infectadas produzem, em média, menos 10-12\% de leite;

- Redução do tempo de vida produtiva das vacas leiteiras devido ao abate involuntário. Este é um dos principais problemas associados à tuberculose bovina, pois aumenta os custos de substituição e de recria de animais. Além disso, pode perturbar o programa de melhoramento genético do rebanho.

Existem também consequências para a economia regional e nacional. As normas veterinárias internacionais que regulam o comércio de animais vivos e de produtos de origem animal requerem que essas mercadorias sejam originárias de países livres de infecção, de áreas, compartimentos ou propriedades livres certificadas. 


\section{OBJETIVOS}

\section{OBJETIVOS GERAIS:}

Caracterizar a situação epidemiológica e subsidiar o planejamento do sistema de vigilância da tuberculose bovina no Estado de Santa Catarina.

\section{OBJETIVOS ESPECÍFICOS:}

- Estimar a prevalência e distribuição geográfica de focos de tuberculose bovina em Santa Catarina

- Estimar a prevalência da tuberculose bovina em fêmeas bovinas adultas em Santa Catarina

- Identificar fatores de risco associados à presença da doença nos rebanhos bovinos de Santa Catarina. 


\section{REFERÊNCIAS}

Anônimo. 1994. Livestock Disease Eradication: Evaluation of the Cooperative State-Federal Bovine Tuberculosis Eradication Program. National Academy Press. Washington D. C.

Acha P.N. \& Szyfres B. 2003. Zoonosis y enfermedades transmisibles comunes al hombre y a los animales: Bacteriosis y micosis. Vol.2. $3^{\text {rd }}$. ed. PAHO, Washington, DC. 396p.

Abrahão R.M.C.M. 1999. Tuberculose humana causada pelo Mycobacterium bovis: considerações gerais e a importância dos reservatórios animais. Dissertação de Mestrado em Saúde Pública, Universidade de São Paulo, São Paulo, SP. 318p.

Alarcon G.J.C., Venegas Y.R., Narvaez L.B., Martínez O.E.P., Casanova L.G. Gallegos S.S., Vargas A.N., Ramírez A.M.O. \& Suazo F.M. Efficacy of a vaccine formula against tuberculosis in cattle. 2013. 8(10):1-7.

Álvarez J., Bezos J., de la Cruz, M.L., Casal, C., Romero, B., Domínguez L., de Juan L. \& Pérez A. 2014. Bovine tuberculosis: within-herd transmission models to support and direct the decision-making process. Research in Veterinary Science. doi: 10.1016/j.rvsc.2014.04.09.

Barrera L., Kantor I.N. 1987. Non-tuberculous mycobacteria and Mycobacterium bovis as a cause of human disease in Argentina. Tropical Geographical Medicine.39:222-227.

Barwinek F., Taylor N.M.1996. Assessment of the socio-economic importance of bovine tuberculosis in turkey and possible strategies for control or eradication. Turkish-German Animal Health Information Project. General Directorate of Protection and Control; Akay Cad, No 3, Bakanlikar, Ankara.

Belchior A.P.C. 2000. Prevalência, distribuição regional e fatores de risco da tuberculose bovina em Minas Gerais. Dissertação de Mestrado em Medicina Veterinária, Escola de Veterinária, Universidade Federal de Minas Gerais, Belo Horizonte, MG. 55p.

Blancou J.M., Cheneau Y.1974. Influence de la tuberculose sur le gain de poids de zebus a l'engrais. Revue d'Elevage et Medicine Veterinaire des Pays Tropicaux. 27:75-80.

Buddle B.M., Skinner M.A., Wedlock D.N., Collins D.M. \& Lisle G.W. 2002a. New generation vaccines and delivery systems for control of bovine tuberculosis in cattle and wildlife. Veterinay Immunology and Immunopathology. 87(2002):177-185.

Caporale V.P., Battelli G., Ghilardi G., Biancardi V.1980. Evaluation of costs and benefits of the control campaigns against bovine tuberculosis, brucellosis, foot-and-mouth disease and swine fever in Italy. Bulletin de l'Offices Internationale des Epizooties.92(5-6):291-304.

Corner L.A., Melville L., McCubbin K., Small K.J., McCormick B.S., Wood P.R. \& Rothel J.S. 1990. Efficiency of inspection procedures for the detection of tuberculous lesions in cattle. Australian Veterinary Journal. 67(11):389-392.

Corner L.A. 1994. Post mortem diagnosis of Mycobacterium bovis infection in cattle. Veterinary Microbiology. 40: 53-63.

Costa L.B. 2012. Tuberculose bovina em regiões de relevância econômica no Estado da Bahia. Dissertação de Mestrado em Ciência Animal nos Trópicos, Escola de Medicina Veterinária e Zootecnia, Universidade Federal da Bahia, Salvador, BA. 121p.

Cosivi O., Grange J.M., Daborn C.J., Raviglione M.C., Fujikura T., Cousins D., Robinson R.A., Huchzermeyer, H.F.A.K., de Kantor I. \& Meslin F.X. 1998. Zoonotic tuberculosis due to Mycobacterium bovis in developing countries. Emerging Infectious Diseases. 4(1):59-70.

de la Rua-Domenech, R. 2006. Human Mycobacterium bovis infection in the United Kingdom: incidence, risks, control measures and review of the zoonotic aspects of bovine tuberculosis. Elsevier. 86(2):77-109.

de Kantor I.N., Nader A., Bernardelli A., Giron D.O. \& Man E. 1987. Tuberculous infection in cattle not detected by slaughterhouse inspection. Journal of Veterinary Medicine B. 34:202-205.

de Kantor I.N. \& Ritacco V. 1994. Bovine tuberculosis in Latin America and the Caribbean: current status, control and eradication programs. Veterinary Microbiology. 40(1994):5-14.

Denes L.1981. Some economic aspects of bovine tuberculosis eradication in Hungary. Bulletin de l'Offices Internationale des Epizooties. 93(5-6):1011-1014.

Essey M.A. \& Koller M.A. 1994. Status of bovine tuberculosis in North America. Veterinary Microbiology. 40(1994):15-22.

Fitzgerald S.D. \& Kaneene J.B. 2012. Wildlife reservoirs of bovine tuberculosis worldwide: hosts, pathology, surveillance, and control. Veterinary Pathology. 50(3):488-499.

Georghiou P., Patel A.M. \& Konstantinous A.1989. Mycobacterium bovis as an occupational hazard in abattoir workers. Aust NZ Journal of Medicine. 19:409-410.

Grange J.M. 1996. Human and bovine tuberculosis - new threats from an old disease (Guest editorial).British Veterinary Journal. 152(1):3-4. 
Griffin J.M., Hahesy T., Lynch K., Salman M.D., McCarthy J. \& Hurley T. 1993. The association of cattle husbandry practices, environmental factors and farmer characteristics with the occurrence of chronic bovine tuberculosis in dairy herds in the Republic of Ireland. Preventive Veterinary Medicine. 17(1993):145-160.

Jacquet J. 1986. Les tuberculoses animales. Bulletin de l'Academie nationale de Medicine. 170(7):915-919.

Latini M.S., Latini O.A., Lopez M.L., Cecconi J.O. 1990. Tuberculosis bovina en seres humanos. Rev. Argentina Torax. 51:13-16.

Meyn A.1953. Die Bekampfung der rindertuberkulose im bund und in den Ladern, land und hauswirtschaftlicher auswertungs und infirmationsdienst. 59:7-22.

Michel A.L., Müller B. \& van Helden P.D. 2010. Mycobacterium bovis at the animal-human interface: a problem, or not? Veterinary Microbiology. 140(2010):371-381.

Munyeme M., Muma J.B., Samui K.L., Skjerve E., Nambota A.M., Phiri I.G.K., Rigouts L. \& Tryland M. 2009. Prevalence of bovine tuberculosis and animal level risk factors for indigenous cattle under different grazing strategies in the livestock/wildlife interface areas of Zambia. 41:345-352.

Néspoli J.M.B. 2012. Situação epidemiológica da tuberculose bovina no Estado de Mato Grosso. Dissertação de Mestrado em Ciências, Faculdade de Medicina Veterinária e Zootecnia, Universidade de São Paulo, São Paulo, SP. $44 \mathrm{f}$.

O’Reilly L.M. \& Daborn C.J.1995. The epidemiology of Mycobacterium bovis infections in animals and man: a review. Tubercule and Lung Disease. 76(supplement 1):1-46.

Palmer M.V. \& Waters W.R. 2006. Advances in bovine tuberculosis diagnosis and pathogenesis: what policy makers need to know. Veterinary Microbiology. 112(2006):181-190.

Parra A., García N., García A., Lacombe A., Moreno F., Freire F., Moran J. \& de Mendoza J.H. 2008. Development of a molecular diagnostic test applied to experimental abattoir surveillance on bovine tuberculosis. Veterinary Microbiology. 127(2008):315-324.

Porphyre T., Stevenson M.A. \& McKenzie J. 2008. Risk factors for bovine tuberculosis in New Zealand cattle farms and their relationship with possum control strategies. Preventive Veterinary Medicine 86(2008):93-106.

Pollock J.M., Welsh M.D. \& McNair J. 2005. Immune responses in bovine tuberculosis: towards new strategies for the diagnosis and control of disease. 108(2005):37-43.

Pritchard D.G.1988. A century of bovine tuberculosis 1888-1988: conquest and controversy. Journal of Comparative Pathology. 99:357-399.

Reilly L.A. \& Courtenay 0. 2007. Husbandry practices, badger sett density and habitat composition as risk factors for transient and persistent bovine tuberculosis on UK cattle farms. Preventive Veterinary Medicine 80(2007):129-142.

Ritacco V., Kantor I.N. 1992. Zoonotic tuberculosis in Latin America. Journal of Clinical Microbiology.30:32993300.

Robinson P., Morris D., Antic R.1988. Mycobacterium bovis as an occupational hazard in abattoir workers. Aust NZ Journal of Medicine.18:701-703.

Ryan T.J., Livingstone P.G., Ramsey D.S.L., de Lisle G.W., Nugent G., Collins D.M. \& Buddle B.M. 2006. Advances in understanding disease epidemiology and implications for control and eradication of tuberculosis in livestock: the experience from New Zealand. Veterinary Microbiology. 112(2006):211-219.

Santos R.L. \& Guedes R.M.C. 2010. Sistema Respiratório, p.1-50. In: Santos R.L. \& Alessi A.C. (Orgs.), Patologia Veterinária. Roca, São Paulo. 892p.

Silva M.C.P. 2012. Epidemiologia e fatores de risco da tuberculose bovina no Paraná. Tese de doutorado em Ciência Animal, Centro de Ciências Agrárias, Universidade Estadual de Londrina, Londrina, PR. 82f.

Schiller I., Oesch B., Vordermeier H.M., Palmer M.V., Harris B.N. Orloski K.A., Buddle B.M., Thacker T.C., Lyashchenko K.P. \& Waters W.R. 2010. Bovine tuberculosis: a review of current and emerging diagnostic techniques in view of their relevance for disease control and eradication. Transboundary and Emerging Diseases. 57(2010):205-220.

Skuce R.A., Allen A.R. \& McDowell, W.J. 2012. Herd-level risk factors for bovine tuberculosis: a literature review. Veterinay Medicine International. 2012:1-10.

Thoen C., LoBue P. \& de Kantor I. 2006. The importance of Mycobacterium bovis as a zoonosis. Veterinary Microbiology. 112(2006):339-345.

Tizard I.R. 2009. Imunologia Veterinária. Elsevier, São Paulo. 587p.

Torgerson P. R. \& Torgerson D.J. 2009. Public health and bovine tuberculosis: what's all the fuss about? Trends in microbiology. 18(2):67-72. 


\title{
CAPÍTULO II
}

\section{Prevalência e fatores de risco da tuberculose bovina no Estado de Santa Catarina}

\begin{abstract}
Several Brazilian states have recently carried out major epidemiological studies to underpin the planning of the national programme for control and eradication of bovine brucellosis and tuberculosis. Such efforts are coordinated by the Ministry of Agriculture, Livestock and Food Supply and have the scientific support of the University of São Paulo and the University of Brasília. In Santa Catarina, the state animal health authority (CIDASC) implemented in 2012 a random sample survey with a view to estimating the prevalence and risk factors for bovine tuberculosis. The state was divided in five geographical regions and in each one of them was taken a simple random sample of bovine herds with adult females. In each selected herd a sample of adult females ( $>2$ years) was tested for bovine tuberculosis with the comparative cervical tuberculin test. In each selected herd was administered a questionnaire to collect data on animal production and management practices that could be associated to the presence of the disease at the herd-level. The results estimated the prevalence of herds with testpositive animals at $0.50 \%$ [IC 95\%: $0.074 \% ; 0.93 \%$ ], whereas the prevalence for adult females was $0.06 \%$ [IC 95\%: 0\%; 0.12\%]. There was no statistically significant difference between regions, both for herd and animal-level prevalence. With regard to the study of risk factors, two logistic regression models were constructed, which identified the larger herd size and the dairy production as the main factors associated to the chance of a herd being positive for bovine tuberculosis. After a preliminary univariable analysis, a standard model-based logistic regression was used to test for confounding and to assess the goodness-of-fit and the discriminatory performance of the predictive model. Then, the same variables were used to develop a design-based model, taking into account the sampling weights of each herd, considering the regions as a sampling strata, which is more appropriate for population inference. Both models gave results of the same magnitude, but the standard errors were wider in the design-based logistic regression, as expected: the Odds Ratio for herds with more than 18 adult females $\left(3^{\text {rd }}\right.$ quartile of the herd-size] was 7.68 [IC 95\%: 1.22\%; 48.39\%] and the dairy farms showed an Odds Ratio of 10.43 [IC 95\%: 2.00\%; 54.25\%] compared to the beef or dual-purpose herds. These results confirm that dairy herds, where animals are kept in partial or full confinement, and larger herds, that tend to be more production intensive and buy more frequently replacement animals, have higher risk of having animals with bovine tuberculosis. Given the low prevalence found for the state and the type of higher risk herds, the surveillance system should be targeted at the main dairy basins, notably the western region, where most intensive dairy herds and industries are placed.
\end{abstract}

INDEX TERMS: bovine tuberculosis, prevalence, risk factors, Santa Catarina.

RESUMO.- Com o intuito de subsidiar o planejamento estratégico do Programa Nacional de Controle e Erradicação da Brucelose e Tuberculose (PNCEBT), diversos Estados brasileiros vêm realizando estudos transversais por amostragem, sob a coordenação do Ministério da Agricultura, Pecuária e Abastecimento (MAPA) e com apoio científico da Universidade de São Paulo (USP) e da Universidade de Brasília (UnB). Em Santa Catarina, a Companhia Integrada de Desenvolvimento Agrícola de Santa Catarina (CIDASC) realizou estudo de prevalência e avaliação de fatores de risco em 2012. O Estado foi dividido em cinco regiões, de forma a considerar a heterogeneidade regional e de ecossistemas produtivos. Em cada região, foi feita uma amostragem independente, em duas etapas: (i) foram selecionadas, aleatoriamente, propriedades com atividade reprodutiva em cada região; e (ii) em cada rebanho uma amostra de fêmeas com idade igual ou superior a dois anos foi submetida à prova da tuberculinização comparada. Aplicou-se um questionário para coleta de dados relativos às características produtivas e práticas de manejo que pudessem estar associados à presença de animais reagentes no rebanho. Os resultados estimaram que a prevalência de propriedades positivas (focos) é de 0,50\% [IC 95\%: 0,074\%; 0,93\%] enquanto a prevalência de tuberculose em fêmeas adultas é de 0,06\% [IC 95\%: 0\%; 0,12\%]. Não houve diferença estatística nas prevalências de focos e de fêmeas positivas entre as cinco regiões. Foram desenvolvidos dois modelos de regressão logística que identificaram como fatores de risco o tamanho do rebanho (rebanhos com mais de 19 fêmeas - 3o quartil) e a finalidade da produção ser leiteira. Primeiramente construiu-se um modelo tradicional, sem considerar o peso amostral de cada propriedade testada para tuberculose bovina, o qual foi depois comparado com um modelo em que o delineamento amostral com estratificação regional foi considerado por via da inclusão dos pesos amostrais de cada propriedade. Este modelo, mais adequado para inferência populacional, revelou que os rebanhos com 19 ou mais fêmeas apresentaram um Odds Ratio (OR) de 7,68 [IC 95\%: 1,22\%; 48,39\%] em relação aos rebanhos menores, enquanto as propriedades leiteiras apresentaram OR de 10,43 [IC 95\%: 2,00\%; 54,25\%] em relação às demais. Os resultados sugerem que os rebanhos leiteiros, onde os animais são mantidos em confinamento parcial ou total, e os rebanhos maiores, que tendem a comprar animais com maior frequência, apres entam maior risco de tuberculose bovina. Considerando a prevalência baixa e a tipologia de propriedades mais afetadas, o sistema de vigilância da tuberculose bovina deve ser dirigido às bacias leiteiras do Estado, com destaque para a região Oeste, onde se concentram as principais indústrias e as propriedades leiteiras de produção mais intensiva.

TERMOS DE INDEXAÇÃO: Tuberculose bovina, prevalência, fatores de risco, Santa Catarina 


\section{INTRODUÇÃo}

A tuberculose bovina afeta a saúde do rebanho, a lucratividade e o comércio e pode prejudicar anos de melhoramento genético, além de gerar impactos negativos aos produtores cujo gado venha a ser acometido (Skuce, Allen \& McDowell 2012). A principal forma de introdução da doença em um rebanho é a aquisição de animais infectados, o que é fortemente influenciado pelas características da unidade de criação, como tipo de exploração, tamanho do rebanho, densidade populacional e práticas zootécnicas e sanitárias (Brasil 2006). Propriedades com exploração pecuária mais intensiva possuem maior tendência à movimentação de animais que favorece a disseminação da doença (Livingstone et al 2006).

A tuberculose bovina representa risco para a saúde pública, ainda que medidas sejam adotadas para evitar sua transmissão ao ser humano. Algumas opiniões consideraram este risco negligenciável, de forma que as maiores preocupações quanto ao controle da tuberculose bovina têm-se voltado, atualmente, para suas implicações comerciais (Skuce, Allen \& McDowell 2012), as quais são de grande relevância para o Brasil, que possui uma importante atividade pecuária.

Com o intuito de organizar a prevenção desta doença e reduzir sua incidência e sua prevalência, o Ministério da Agricultura, Pecuária e Abastecimento (MAPA) instituiu o Programa Nacional de Controle e Erradicação da Brucelose e Tuberculose - PNCEBT (Brasil 2001, Brasil 2004). Entre as ações deflagradas pelo MAPA a partir da instituição do PNCEBT, destacava-se o propósito de estabelecer critérios para a realização de estudos de prevalência da tuberculose no país. As notificações oficiais de tuberculose bovina, entre os anos de 1989 e 1998, indicaram uma prevalência média nacional de 1,3\% de animais infectados entre os testados (Brasil 2006). Estes dados não são representativos da população bovina nacional, já que se referem a animais sujeitos a testes regulares, muitas vezes mais do que uma vez ao ano. Embora, aparentemente, a prevalência não seja muito elevada, a doença encontra-se presente em todo o território nacional, devendo ser objeto de medidas de mitigação dos riscos aos animais e à população humana.

Assim, com o intuito de estimar a prevalência da tuberculose bovina na população, foram realizados estudos transversais por amostragem em vários estados da federação. Em Minas Gerais, Belchior (2000) estimou uma prevalência geral de 5,02\% (IC 95\%: 4,67\% - 5,37\%) de rebanhos positivos e 0,8\% de fêmeas e machos com idade igual ou superior a 24 meses positivos para tuberculose e apontou como fatores de risco: sistemas de produção de leite e misto; grupo genético racial especializado em leite; sistema de ordenha mecanizado; resfriamento do leite por resfriador ou tanque de expansão e monitoramento da produção por software. Nenhuma destas variáveis tem relação causal com a doença, mas todas são indicadores indiretos do alto grau de intensificação da produção leiteira.

Silva (2012) estimou, no Estado do Paraná, a prevalência de propriedades positivas para tuberculose em 2,15\% (IC 95\%: 1,31\% - 3,00\%) e de fêmeas e machos em idade superior a 24 meses em 0,42\% (IC 95\%: 0,04\% $0,81 \%)$. Os fatores de risco associados à presença da tuberculose foram: rebanho adulto com mais de 22 bovinos $\mathrm{e}$ prática de ordenha mecanizada na propriedade. Os dados sugeriram que a chance de detecção da doença aumentava em rebanhos leiteiros maiores e com ordenha mecânica, ou seja, com maior nível de tecnificação.

No Mato Grosso, a prevalência de focos de tuberculose bovina foi estimada em 1,3\% (IC 95\%: 0,7\% 2,4\%) e, nas fêmeas e machos reprodutores com idade igual ou superior a 24 meses, em 0,123\% (IC 95\%: 0,034\% - 0,440\%), de acordo com Néspoli (2012). 0 autor chamou a atenção para a predominância de propriedades de corte no Estado, nas quais foram encontradas as menores prevalências em todos os circuitos produtores, exceto no pantanal. Estes dados, segundo o autor, sugerem fortemente uma associação entre a tuberculose bovina e a atividade leiteira.

Na Bahia, Costa (2012) estimou em 1,6\% a prevalência de focos e em $0,21 \%$ a prevalência da doença em fêmeas e machos com idade igual ou superior a 24 meses. No estudo dos fatores de risco, a autora detectou que as explorações leiteira e mista e rebanhos com mais de 18 fêmeas em idade igual ou superior a 24 meses apresentaram maior chance de detecção da tuberculose bovina.

A atividade leiteira, associada aos rebanhos maiores ou com maior grau de tecnificação, foi, portanto, uma característica apontada pelos estudos conduzidos no Brasil como fator de risco para a tuberculose bovina. Este fato reforça a necessidade de permanente vigilância da doença nas regiões de produção mais expressiva de leite no país.

Santa Catarina possui uma área territorial de 95.736,165 km² (IBGE 2014a). Predomina o clima subtropical úmido, com temperaturas médias variando entre 13 e $25^{\circ} \mathrm{C}$ e chuvas distribuídas durante todo o ano e quatro estações bem definidas (Santa Catarina 2014a). O Estado situa-se na região sul do Brasil, em que a média anual de precipitação varia de 1.250 a $2.000 \mathrm{~mm}$, com exceção do Oeste catarinense, cujo valor ultrapassa os 2.000 mm (INPE 2014). As condições climáticas e o relevo contribuem para que a atividade agrícola de Santa Catarina seja de grande relevância nacional (Santa Catarina 2014b).

Na pecuária, desponta na produção de suínos, sendo o maior exportador de carne suína do Brasil, com um volume de quase $25 \%$ das exportações nacionais e, na produção de aves, ocupa o segundo lugar na pauta de exportações nacionais de carne de frango (IBGE 2014b). A bovinocultura catarinense é caracterizada pelo minifúndio: em 2012, o Estado contabilizava 4.072 .960 de bovinos (IBGE 2014c) produzidos em aproximadamente 
200 mil propriedades. Destaca-se o reconhecimento do Estado como livre de febre aftosa sem vacinação pela Organização Mundial de Saúde Animal (OIE) desde 2007 (OIE 2014).

Neves (2014) observou que os rebanhos bovinos catarinenses apresentam uma mediana de 10 e uma média de 28 animais. Ainda assim, o Estado apresenta-se como o quinto maior produtor nacional de leite, de acordo com a Embrapa (2012). A produção leiteira catarinense, em 2011, alcançou aproximadamente 2,5 bilhões de litros, equivalente a cerca de 7,8\% da produção brasileira. Segundo Neves (2014), o Estado se caracteriza pela grande diversidade produtiva regional, sendo que as propriedades leiteiras são fortemente predominantes na região Oeste, enquanto na região da Grande Florianópolis e Sul Catarinense, predominam propriedades de exploração mista e no Vale do Itajaí destaca-se o equilíbrio entre as finalidades de exploração. Nas regiões Norte e Serrana do Estado, a bovinocultura de corte é a mais relevante. 0 mesmo autor destaca que 33,21\% das propriedades leiteiras ou mistas em Santa Catarina produzem no sistema de semiconfinamento e que, embora a forma de ordenha manual seja predominante no Estado, na região Oeste apenas 32,7\% dos produtores ainda recorrem a esta prática. Nesta região, $12 \%$ das propriedades amostradas possuem sala de ordenha e 48,7\% recorrem à prática de inseminação artificial. Estes dados revelam a incorporação de tecnologia ao sistema produtivo catarinense, particularmente na região Oeste, onde predomina a atividade leiteira.

Quanto à tuberculose bovina, dados apresentados pelos CRMV-PR, CRMV-SC \& CRMV-RS (2009) indicam que, no ano de 2008, foram testados 82.476 animais em Santa Catarina - aproximadamente 2,22\% do rebanho estadual. Destes, 853 foram reagentes positivos para a tuberculose, correspondendo a 1,03\% dos animais testados e a $0,022 \%$ do rebanho. Estes animais se apresentaram nos 196 focos detectados no território estadual.

Embora estes dados demonstrem a presença da doença no território estadual, não são representativos da bovinocultura catarinense, fazendo-se necessária a realização de um estudo populacional por amostragem. 0 presente trabalho, portanto, possuiu o objetivo de estimar a prevalência e a distribuição geográfica de rebanhos bovinos infectados com tuberculose no Estado de Santa Catarina, bem como identificar tipos de produção, práticas de manejo e fatores de risco que possam estar associados à presença da doença.

\section{MATERIAL E MÉTODOS}

Realizou-se um estudo transversal por amostragem no Estado de Santa Catarina com o objetivo de estimar a prevalência e fatores de risco da tuberculose nos rebanhos bovinos do Estado, no âmbito do PNCEBT. A população-alvo foram as propriedades dedicadas à bovinocultura, excluindo-se as que não possuem animais adultos com finalidade reprodutiva.

O presente estudo compõe um projeto cooperativo firmado entre o MAPA e os órgãos estaduais de Defesa Sanitária Animal, o Laboratório de Epidemiologia e Bioestatística da Universidade de São Paulo (LEB/VPS/FMVZ/USP) e o Laboratório de Epidemiologia Veterinária da Universidade de Brasília (Epiplan/FAV/UnB).

\section{Diagnóstico de tuberculose}

O diagnóstico de tuberculose foi efetuado por um método indireto, a prova de tuberculinização intradérmica cervical comparada (TCC), conforme descrito pelo regulamento técnico do PNCEBT (Brasil 2004). Animais inconclusivos foram retestados com intervalo mínimo de 60 dias entre os testes e, caso apresentassem dois resultados inconclusivos consecutivos, seriam considerados reagentes positivos.

\section{Amostragem}

O Estado de Santa Catarina foi dividido em cinco regiões distintas, conforme ilustrado no Mapa 1, definidas de acordo com as características dos sistemas de produção, manejo dos animais, finalidade da exploração, tamanho médio de rebanhos e sistema de comercialização. As regiões aproximam-se da divisão realizada pelo IBGE em mesorregiões brasileiras; quais sejam: Região 1 - Serrana; Região 2 - Grande Florianópolis e Sul Catarinense; Região 3 - Oeste Catarinense; Região 4 - Norte Catarinense; Região 5 - Vale do Itajaí. Esta divisão vem sendo usada pelas autoridades sanitárias do Estado para fins de regionalização das ações sanitárias. 
Mapa 1. Divisão do Estado de Santa Catarina em regiões, segundo a característica produtiva e de comercialização.

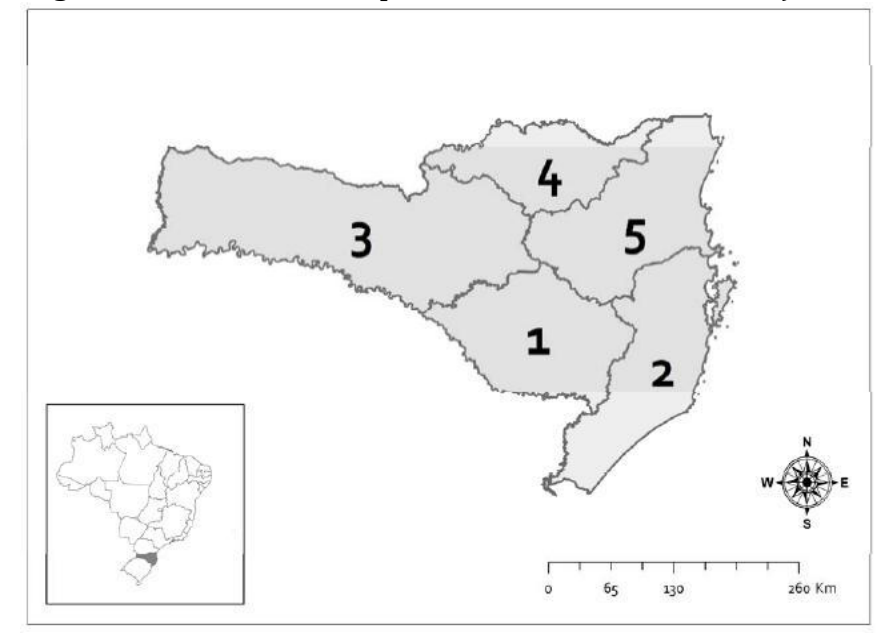

Foram amostradas propriedades em todos os 293 municípios do Estado. 0 processo amostral foi realizado em dois estágios: (i) em cada região, foram selecionadas, aleatoriamente, propriedades com atividade reprodutiva, que constituíram as unidades primárias de amostragem; e (ii) nos rebanhos principais destas propriedades, foram amostradas, aleatoriamente, fêmeas com idade igual ou superior a dois anos, que constituíram as unidades secundárias de amostragem.

Os tamanhos amostrais foram calculados segundo a fórmula descrita por Petrie \& Watson (2009), utilizando-se a ferramenta Epitools ${ }^{\circledR}$ (Sergeant 2014). 0 número mínimo de unidades primárias de amostragem (propriedades) estabelecido, por região, foi de 292 propriedades, considerando o método de amostragem aleatória simples e os seguintes parâmetros: prevalência estimada ( $\mathrm{P}=5 \%)$, precisão desejada $( \pm 2,5 \%)$ e nível de confiança $(95 \%)$.

Para o cálculo das unidades secundárias de amostragem, assumiu-se uma prevalência intra-rebanho de $15 \%$, a partir de informações fornecidas por pesquisadores que realizaram estudos prévios de tuberculose bovina em Minas Gerais, Bahia e Paraná. Foram executadas simulações, com diferentes tamanhos de rebanhos e de amostras de animais e diferentes pontos de corte, utilizando-se a ferramenta Epitools ${ }^{\circledR}$ (Sergeant 2014). Adotou-se o critério que permitisse obter sensibilidade e especificidade agregadas, em nível de rebanho, de, no mínimo, 90\%. A sensibilidade e especificidade assumidos para o TCC foram de 77,5\% e 99,5\%, respectivamente, com base em Lôbo (2008), que indicou serem esses os valores mais prováveis de sensibilidade e especificidade do teste, usando uma distribuição de Pert para modelar as características do TCC a partir de valores encontrados na literatura científica.

Foram excluídas das amostras as fêmeas que estivessem no período de peri-parto, ou seja, em aproximadamente 15 dias antes e 15 dias após o parto, conforme recomendado por Brasil (2006), já que, neste intervalo, há risco de redução da reatividade dos animais, que se apresentam como potenciais falsos-negativos.

A escolha dos animais a serem amostrados foi feita pelo método de amostragem aleatória simples (Petrie \& Watson, 2009), usando uma tabela de números aleatórios para sortear os animais. A amostragem de animais foi executada da seguinte forma: nos rebanhos com até 20 fêmeas em idade igual ou superior a dois anos, foram testadas todas as fêmeas nesta faixa etária; nos rebanhos com mais de 20 e até 99 fêmeas em idade igual ou superior a dois anos, foram testadas 20 fêmeas nesta faixa etária e, em rebanhos com mais de 99 fêmeas em idade igual ou superior a dois anos, foram testadas 40 fêmeas nesta faixa etária. Em rebanhos com até 99 fêmeas elegíveis para teste, a detecção de pelo menos um animal positivo no teste classificava o rebanho como positivo. Os rebanhos com mais de 99 fêmeas só seriam classificados como positivos se ocorressem pelo menos dois testes positivos entre as 40 fêmeas testadas.

O Quadro 1 resume os dados censitários e tamanho final das amostras, após sorteio das propriedades por município, para cada região produtora 
Quadro 1. Dados censitários da população bovina do estado de Santa Catarina em 2012, segundo a região produtora.

\begin{tabular}{ccccc}
\hline \multirow{2}{*}{ Região } & \multicolumn{2}{c}{ Propriedades com atividade reprodutiva } & \multicolumn{2}{c}{ Fêmeas $\geq 24$ meses } \\
\cline { 2 - 5 } & Existentes & Amostradas & Existentes & Amostradas \\
\hline 1 & 15.373 & 310 & 283.064 & 2.977 \\
2 & 40.975 & 328 & 275.401 & 1.587 \\
3 & 86.598 & 368 & 1.107 .212 & 3.857 \\
4 & 12.826 & 307 & 96.917 & 1.769 \\
5 & 43.402 & 340 & 266.871 & 1.460 \\
\hline SC & 199.174 & 1.653 & 2.029 .465 & 11.650 \\
\hline
\end{tabular}

\section{Operacionalização}

A realização dos exames nos animais e a aplicação dos questionários ocorreram no período de junho a dezembro do ano de 2012, por médicos veterinários da Companhia Integrada de Desenvolvimento Agrícola de Santa Catarina (CIDASC), órgão estadual responsável pelo serviço de defesa sanitária animal. Os profissionais envolvidos no estudo receberam treinamentos com o objetivo de padronização dos métodos e dos questionários e, a eles, foi disponibilizado um manual contendo todas as instruções operacionais.

Os rebanhos receberam um código individual e, para todas as propriedades, foram obtidas as coordenadas geográficas no formato de graus, minutos e segundos decimais e a altitude. Foi efetuada uma visita inicial às propriedades sorteadas, em que se procedeu a aplicação do questionário, cujo objetivo foi o de coletar os dados que viabilizariam a análise de possíveis associações entre a ocorrência da tuberculose e as práticas de manejo e características produtivas. Os campos do questionário remetiam à característica produtiva dos rebanhos amostrados, às práticas gerais de produção e de manejo sanitário e a alguns aspectos de interesse em saúde pública, conforme descrito a seguir:

a) Tipo de exploração - categorias: "Corte"; "Leite" ou "Misto". Como Corte, foram classificadas as propriedades cuja produção principal era constituída por rebanhos destinados a cria, recria e engorda, em ciclo completo, ou em alguma destas etapas isoladamente. Seu objetivo principal deveria ser a engorda e o abate dos animais para produção de carne. Nestas propriedades, a presença de bovinos para produção de leite para consumo próprio não descaracterizava o rebanho como sendo de corte.

Os rebanhos classificados como Leite foram aqueles cuja atividade majoritária era a produção leiteira, independente do destino dado ao leite produzido - consumo, venda ou benefício. Na categoria Misto, foram incluídos os rebanhos dedicados tanto à produção de carne, em ciclo completo ou parcial de cria, recria e engorda, quanto à atividade leiteira. Nesta categoria, os rebanhos de corte e de leite compartilhavam ambientes e instalações.

Para os rebanhos classificados como Leite ou Misto, o número de ordenhas realizadas por dia foi registrado como: "não ordenha"; "uma ordenha por dia" ou "duas ordenhas por dia"; a forma de ordenha, enquadrada como: "ordenha manual"; "mecânica ao pé" ou "mecânica em sala de ordenha".

b) Tipo de criação - categorias: "Confinado"; "Semiconfinado" ou "Extensivo". Os rebanhos inseridos na categoria Confinado foram aqueles nos quais os animais eram produzidos e alimentados, de forma sistemática e controlada, em espaço limitado e reduzido. Como Semiconfinado, entendeu-se o rebanho mantido em pastagem, ao qual se fornecia alguma forma de suplementação alimentar ao longo do ano ou em parte dele. Nos rebanhos da categoria Extensivo, os animais eram produzidos exclusivamente em regime de pasto, aos quais poderia ou não ser fornecido concentrado proteico e/ou sal mineral.

c) Tamanho do Rebanho - população de bovinos existente na propriedade, estratificada em: "Machos castrados"; "Machos entre 0 e 6 meses"; "Machos entre 6 e 12 meses"; "Machos entre 12 e 24 meses"; "Machos acima de 24 meses"; "Fêmeas entre 0 e 6 meses"; "Fêmeas entre 6 e 12 meses"; "Fêmeas entre 12 e 24 meses"; "Fêmeas acima de 24 meses".

"aves".

d) Existência de outras espécies domésticas na propriedade - opções (cumulativo): "equinos"; "suínos",

e) Existência de espécies silvestres de vida livre na propriedade - opções (cumulativo): "cervídeos"; "capivaras"; "marsupiais"; "felídeos silvestres" e "primatas silvestres".

f) Variáveis dicotômicas - opções "sim" ou "não": "Exigência de teste de tuberculose para aquisição de animais"; "Aluguel de pasto em alguma época do ano"; "Existência de pastos em comum com outras propriedades"; "Aquisição de fêmeas ou machos com finalidade de reprodução"; "Venda de fêmeas ou machos com finalidade de reprodução"; "Compartilhamento de aguada ou bebedouros com outras propriedades"; "Compartilhamento de insumos com outras propriedades"; "Compartilhamento de equipamentos com outras propriedades"; "Compartilhamento de funcionários com outras propriedades"; "Existência de áreas alagadas na propriedade"; "Existência de áreas de concentração de animais na propriedade"; "Existência de áreas para pouso de boiada em trânsito". Urbana".

g) Classificação da propriedade - categorias: "Rural Clássica"; "Aldeia Indígena”; "Assentamento"; "Periferia 
Dohoo, Martin \& Stryhn (2010) chamam a atenção para as limitações apresentadas pelos estudos transversais quando o objetivo é o de se observar potenciais fatores de risco e Rothman, Greenland \& Lash (2008) explicam que uma das limitações consiste na dificuldade em se determinar a ordem temporal da ocorrência dos eventos. Por este motivo, destaca-se que a análise das variáveis descritas no presente estudo e sua associação com a ocorrência da tuberculose não possui o propósito de estabelecer vínculos de causalidade e, sim, apenas caracterizar o perfil dos rebanhos e suas práticas produtivas, nos quais a tuberculose apresenta maior chance ocorrência.

\section{Análises estatísticas}

Os cálculos da estimativa de prevalência de propriedades e de animais positivos no Estado foram executados com o auxílio do software STATA ${ }^{\circledR}$ versão 12 . Dentro de cada região em que foi realizada a amostragem aleatória simples de propriedades, a estimativa da prevalência de tuberculose em rebanhos baseou-se na razão entre propriedades classificadas como positivas na amostra e o total de propriedades amostradas naquela região.

Para a estimativa da prevalência de propriedades com tuberculose (focos) em todo o Estado, houve a necessidade de se considerar que a amostragem das propriedades em cada região não foi proporcional ao número de propriedades existentes nas respectivas regiões; portanto, as amostras de cada região contribuíram com pesos diferentes para o cálculo da prevalência estadual.

A forma mais comum de obtenção dos pesos amostrais, segundo Dohoo, Martin \& Stryhn (2010), é a utilização do inverso da probabilidade de seleção da amostra, cujo resultado reflete o número de indivíduos da população que cada indivíduo da amostra representa. Assim, para o cálculo de prevalência de propriedades em todo o Estado, foi efetuada uma ponderação utilizando o peso $\mathrm{P}_{1}$, exercido por cada propriedade amostrada em cada uma das regiões:

$$
P_{1}=\frac{\text { Número de propriedades existentes na região }}{\text { Número de propriedades amostradas na região }}
$$

Para a estimativa da prevalência de tuberculose em vacas de idade igual ou superior a dois anos, o cálculo considerou a amostragem feita em dois estágios, sendo as propriedades os clusters em cujos rebanhos foram amostradas vacas em idade igual ou superior a 24 meses. Assim, para o cálculo da prevalência estadual desta categoria animal, foi efetuada uma ponderação, considerando-se o peso $\mathrm{P}_{2}$ exercido por cada vaca de idade igual ou superior a dois anos amostrada em relação ao seu rebanho e, em seguida, na respectiva região:

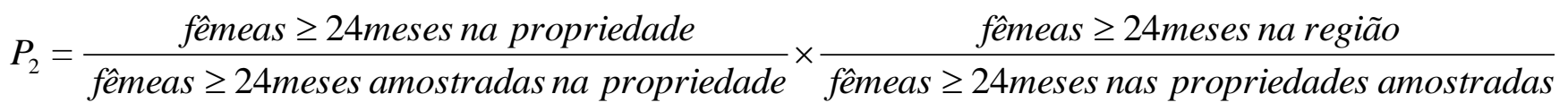

Os cálculos de prevalência foram executados com o auxílio do software STATA ${ }^{\circledR}$, versão 12 (módulo: Statistics $\rightarrow$ Summaries, tables and tests $\rightarrow$ Proportion). A prevalência em vacas adultas considerou a amostragem em multiestágio ([aba]: SE/Cluster $\rightarrow$ Survey data estimation $\rightarrow$ Survey settings... $\rightarrow$ Number of stages $\rightarrow 2:$ primeiro estágio, propriedades; segundo estágio, vacas de idade igual ou superior a dois anos). Os intervalos de confiança da prevalência em propriedades nas regiões foram obtidos pela Distribuição Binomial Exata (módulo: Statistics $\rightarrow$ Summaries, tables and tests $\rightarrow$ Confidence Intervals).

Os possíveis fatores de risco foram identificados por meio da análise bivariada, pelo teste do Qui-quadrado (Petrie \& Watson 2009). As variáveis que apresentaram valor-p $\leq 0,20$ foram selecionadas para compor o modelo de regressão logística, pelo método da eliminação hierárquica (hierarchical backward elimination procedure), que foi elaborado em dois formatos, conforme sugerido por Hosmer, Lemeshow \& Sturdivant (2013): (i) model-based, destinado a amostragens aleatórias simples, utilizado para seleção das variáveis que compõem o modelo final, para avaliação do ajuste do modelo usando a razão de máxima verossimilhança, e para avaliação do poder discriminatório do modelo; e (ii) design-based, que considera o peso de cada propriedade amostrada nas cinco regiões de amostragem do Estado, utilizado para inferência populacional do efeito dos fatores de risco.

Para a elaboração do modelo de regressão logística no formato model-based e avaliação de sua capacidade discriminatória através da curva ROC (Receiver Operating Characteristic), foi utilizado o software STATA ${ }^{\circledR}$, versão 12 (módulo: Statistics $\rightarrow$ Binary outcomes $\rightarrow$ Logistic Regression (reporting odds ratios) $\rightarrow$ [aba] Model: Dependent variable $\rightarrow$ Independent variables $\rightarrow$ submit $\rightarrow$ [linha de comando] lroc).

Para o modelo logístico no formato design-based, foi utilizado o software STATA ${ }^{\circledR}$, versão 12 (módulo: Statistics $\rightarrow$ Binary outcomes $\rightarrow$ Logistic Regression (reporting odds ratios) $\rightarrow$ SE/Robust $\rightarrow$ Survey data estimation $\rightarrow$ Survey settings... $\rightarrow$ [aba] Main $\rightarrow$ Number of stages $\rightarrow$ Stage 1: propriedades $\rightarrow$ Strata: regiões $\rightarrow$ [aba] Weights $\rightarrow$ Sampling weight variable: peso atribuído a cada propriedade por região $\rightarrow$ [aba] Model: Dependent variable $\rightarrow$ Independent variables). 


\section{RESULTADOS}

Dos 11.650 animais amostrados em Santa Catarina, nove foram classificados como positivos para tuberculose em oito das 1.653 propriedades amostradas; isto significa que, em uma delas, dois animais foram considerados positivos, enquanto nos demais focos, apenas um animal reagiu positivamente ao teste. 0 Mapa 2, elaborado com auxílio do software QuantumGis ${ }^{\circledR}$ versão 2.0.1 representa, graficamente, a localização dos rebanhos positivos.

Mapa 2. Propriedades positivas para tuberculose no inquérito epidemiológico executado em Santa Catarina, 2012 - 2013.

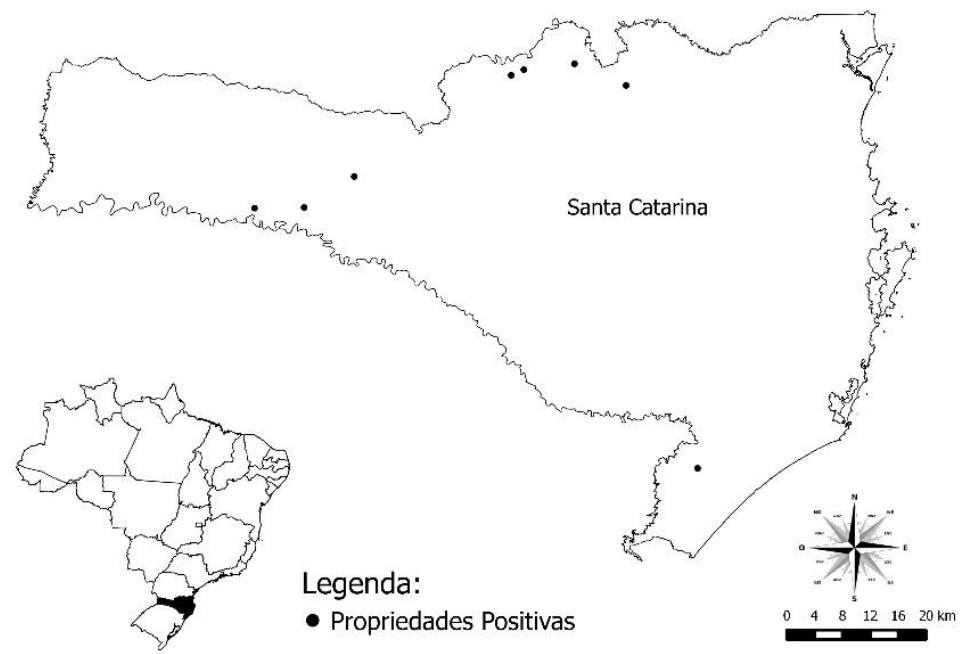

Os cálculos ponderados estimaram 0,50\% [IC 95\%: 0,074\%; 0,93\%] de prevalência de tuberculose em propriedades e 0,06\% [IC 95\%: 0\%; 0,12\%] de fêmeas com idade igual ou superior a dois anos positivas para tuberculose no rebanho catarinense. Nos Quadros 2 e 3, encontram-se a proporção de propriedades e de animais, respectivamente, classificados como positivos em cada região.

Quadro 2. Prevalência de propriedades positivas para tuberculose em Santa Catarina por Região.

\begin{tabular}{ccccc}
\hline Região & № propriedades positivas & Prevalência aparente (\%) & \multicolumn{2}{c}{ Intervalo de Confiança a 95\% (\%) } \\
\hline 1 & 0 & 0,00 & 0,00 & 1,18 \\
2 & 1 & 0,30 & 0,00 & 1,69 \\
3 & 3 & 0,82 & 0,17 & 2,36 \\
4 & 4 & 1,30 & 0,35 & 3,30 \\
5 & 0 & 0,00 & 0,00 & 1,08 \\
\hline SC & 8 & 0,50 & 0,074 & 0,93 \\
\hline
\end{tabular}

Quadro 3. Prevalência de fêmeas em idade reprodutiva (igual ou superior a 24 meses) positivas para tuberculose em Santa Catarina por região.

\begin{tabular}{ccccc}
\hline Região & № animais positivos & Prevalência aparente (\%) & \multicolumn{2}{c}{ Intervalo de Confiança a 95\% (\%) } \\
\hline 1 & 0 & 0,00 & - & - \\
2 & 1 & 0,04 & 0,00 & 0,13 \\
3 & 3 & 0,08 & 0,00 & 0,19 \\
4 & 5 & 0,19 & 0,00 & 0,43 \\
5 & 0 & 0,00 & - & - \\
\hline SC & 9 & 0,06 & 0,00 & 0,12 \\
\hline
\end{tabular}

Os valores de prevalência em fêmeas adultas observados no presente estudo revelam que a especificidade do TCC foi, na realidade, superior ao considerado preliminarmente com base em Lôbo (2008), tendo sido muito próximo a 100\%. Este fato pode ser considerado em estudos posteriores, para determinação do tamanho da amostra de animais por rebanho em função dos tamanhos dos rebanhos, da sensibilidade e especificidade agregadas, em nível de rebanho, e do ponto de corte.

Por ter sido muito baixa a prevalência encontrada e, portanto, muito reduzido o número de casos em algumas categorias das variáveis, dificultando a análise de regressão logística, algumas delas foram reagrupadas em apenas duas categorias. Quanto ao tipo de produção, formaram-se as categorias "Extensivo" versus "Confinado ou Semiconfinado"; e, quanto à finalidade da produção, foram comparadas as categorias "Leite" versus "Corte ou Misto". 
Quanto ao tamanho, optou-se por dividir os rebanhos em duas categorias: "rebanhos com até 18 fêmeas" e "rebanhos com 19 ou mais fêmeas", já que a quantidade de 18 fêmeas, no somatório de todas as faixas etárias, representava o terceiro quartil da distribuição. Esta informação destaca o fato de que, em Santa Catarina, a grande maioria das propriedades possui rebanhos bovinos pequenos, de forma que os rebanhos com 19 ou mais fêmeas, que correspondem a apenas $25 \%$ das propriedades, podem ser considerados relativamente grandes para os padrões catarinenses.

O ponto de corte arbitrado para seleção das variáveis que deveriam compor o modelo de análise de regressão logística foi o nível de significância de $\mathrm{p} \leq 0,20$ na análise bivariada, conforme descrito no Quadro 4 . As variáveis que cumpriram este requisito foram: "tamanho do rebanho bovino, por número de fêmeas"; "tipo de exploração"; "tipo de ordenha" e "aquisição de fêmeas ou machos com finalidade de reprodução".

Quadro 4. Variáveis com valor-p $\leq 0,20$ analisadas quanto à associação com a ocorrência de tuberculose no rebanho catarinense, número de casos e controles em cada categoria e p-valor.

\begin{tabular}{|c|c|c|c|c|}
\hline Variável & & Casos & Controles & p-valor \\
\hline \multirow[t]{3}{*}{ № de fêmeas no rebanho } & & & & 0,001 \\
\hline & Até 18 fêmeas & 2 & 1.240 & \\
\hline & 19 ou mais fêmeas & 6 & 405 & \\
\hline \multirow[t]{3}{*}{ Tipo de exploração } & & & & 0,004 \\
\hline & Leite & 6 & 474 & \\
\hline & Corte ou misto & 2 & 1.161 & \\
\hline \multirow[t]{4}{*}{ Número de ordenhas } & & & & 0,116 \\
\hline & Não ordenha & 2 & 559 & \\
\hline & Uma ordenha & 0 & 382 & \\
\hline & Duas ou três ordenhas & 6 & 662 & \\
\hline \multirow[t]{5}{*}{ Tipo de ordenha } & & & & 0,000 \\
\hline & Não ordenha & 2 & 528 & \\
\hline & $\begin{array}{l}\text { Mecânica em sala de } \\
\text { ordenha }\end{array}$ & 3 & 72 & \\
\hline & Mecânica ao pé & 3 & 268 & \\
\hline & Manual & 0 & 705 & \\
\hline \multirow[t]{3}{*}{$\begin{array}{l}\text { Aquisição de fêmeas ou machos com } \\
\text { finalidade de reprodução }\end{array}$} & & & & 0,187 \\
\hline & Não & 3 & 979 & \\
\hline & Sim & 5 & 642 & \\
\hline
\end{tabular}

As variáveis "tipo de ordenha" e "tipo de exploração" estão fortemente associadas, motivo pelo qual apenas a variável "tipo de exploração" foi selecionada para compor o modelo de regressão logística.

As variáveis selecionadas, portanto, para composição do modelo de regressão logística, foram: “№ de fêmeas no rebanho"; "tipo de exploração" e "aquisição de fêmeas ou machos com finalidade de reprodução". Após as análises, permaneceram no modelo final as variáveis: "№ de fêmeas no rebanho" e "tipo de exploração", conforme apresentado no Quadro 5, no formato model-based da regressão logística (Hosmer, Lemeshow \& Sturdivant 2013).

Quadro 5. Modelo de regressão logística no formato model-based (Hosmer, Lemeshow \& Sturdivant 2013).

\begin{tabular}{lllll}
\hline Variável & & Odds Ratio & IC 95\% & p-valor \\
\hline $\begin{array}{l}\text { Tamanho do rebanho bovino, por } \\
\text { número de fêmeas }\end{array}$ & & & & 0,022 \\
& Até 18 fêmeas & Referência & & \\
& 19 ou mais fêmeas & 6,71 & 1,32 & 34,17 \\
Tipo de exploração & & & & 0,049 \\
& Corte ou misto & Referência & & \\
& Leite & 5,13 & 1,01 & 26,17 \\
\hline
\end{tabular}

De acordo com os resultados observados no quadro 5, a chance de se encontrar tuberculose em rebanhos com 19 ou mais fêmeas foi 6,71 [IC 95\%: 1,32; 34,17] vezes maior do que em rebanhos com até 18 fêmeas; propriedades especializadas na produção de leite apresentaram 5,13 [IC 95\%: 1,01; 26,17] vezes a chance de detecção de tuberculose em relação às de corte ou mistas. Os intervalos de confiança muito amplos dos valores de 
Odds Ratio refletem o número pequeno de casos encontrados. 0 teste da Razão de Verossimilhança (Likelihood Ratio) para o modelo demonstrou significância estatística (valor-p = 0,0012) e a curva ROC, ilustrada pelo Gráfico 1 , revela seu poder discriminatório. A área abaixo da curva (Area Under the Curve - AUC) foi de 0,8135, o que revela uma boa capacidade global do modelo em discriminar rebanhos positivos dos negativos, para uma série de pontos de corte, conforme descrito por Dohoo, I., Martin, W. \& Stryhn, H. (2010).

Gráfico 1. Curva ROC do modelo de Regressão Logística.

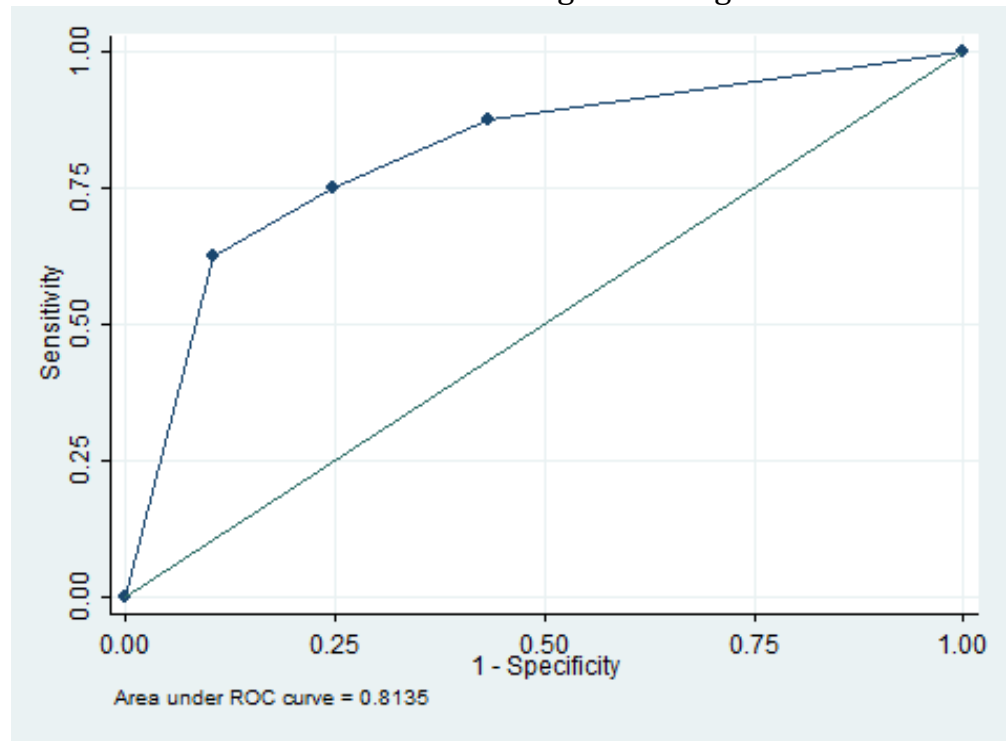

0 modelo de regressão logística no formato design-based (Hosmer, Lemeshow \& Sturdivant 2013), considerando os pesos amostrais das propriedades por região, encontra-se detalhado no Quadro 6.

Quadro 6. Modelo de regressão logística no formato design-based (Hosmer, Lemeshow \& Sturdivant 2013), considerando os pesos amostrais das propriedades em cada região.

\begin{tabular}{lllll}
\hline Variável & & Odds Ratio & IC 95\% & p-valor \\
\hline No de fêmeas no rebanho & & & & 0,030 \\
& Até 18 fêmeas & Referência & & \\
& 19 ou mais fêmeas & 7,68 & 1,22 & 48,39 \\
Tipo de exploração & & & & 0,005 \\
& Corte ou misto & Referência & & \\
& Leite & 10,43 & 2,00 & 54,25 \\
\hline
\end{tabular}

De acordo com o modelo de regressão logística no formato design-based (Hosmer, Lemeshow \& Sturdivant 2013), a chance de se encontrar tuberculose em rebanhos com 19 ou mais fêmeas foi 7,68 [IC 95\%: 1,22; 48,39] vezes maior do que em rebanhos com até 18 fêmeas; propriedades especializadas na produção de leite apresentaram 10,43 [IC 95\%: 2,00; 54,25] vezes a chance de detecção de tuberculose em relação às de corte ou mistas. Comparando os resultados dos dois modelos de regressão, pode ser observado que os Odds Ratio são diferentes mas da mesma magnitude de valores, enquanto os erros amostrais aumentam consideravelmente, de acordo com o que está descrito na literatura (Hosmer, Lemeshow \& Sturdivant 2013). A interpretação da razão de chances é a mesma para ambos os modelos, apesar dos valores do modelo com os pesos das unidades de amostragem (propriedades) representar melhor a população sob estudo.

\section{DISCUSSÃo}

O presente estudo demonstrou que a prevalência de propriedades e de fêmeas adultas positivas para a tuberculose bovina é baixa em todas as regiões de Santa Catarina. Os modelos de regressão logística produzidos nos formatos design-based e model-based indicaram, como fatores de risco para a tuberculose bovina em Santa Catarina, as propriedades serem leiteiras e os rebanhos possuírem 19 ou mais fêmeas, o que corresponde ao último quartil do número de fêmeas por propriedade. 
Os resultados obtidos pelo formato do modelo design-based de regressão logística são mais adequados para inferência populacional, já que considera os pesos das propriedades por região amostrada. No presente estudo, cada propriedade amostrada na região 3 (Oeste) representou 235,3 propriedades, enquanto as unidades primárias de amostragem da região 4 (Norte) representaram apenas 41,8 propriedades, o que reforça a importância de considerar os pesos amostrais no modelo analítico. Deve ser ressaltado que, para fins de diagnóstico do modelo, o formato design-based é de maior complexidade e as técnicas disponíveis ainda necessitam aprimoramento (Hosmer, Lemeshow \& Sturdivant 2013), fato que justifica o uso do modelo simples para avaliação do ajuste modelo e de seu desempenho preditivo.

Os fatores de risco encontrados no presente trabalho são compatíveis com os achados de Belchior (2000), Silva (2012), Néspoli (2012) e Costa (2012), e sugerem que os rebanhos leiteiros, onde os animais são mantidos em confinamento parcial ou total, e os rebanhos maiores, que tendem a comprar animais com maior frequência, apresentam maior risco de tuberculose bovina. Considerando a prevalência baixa e a tipologia de propriedades mais afetadas, o sistema de vigilância da tuberculose bovina deve ser dirigido às bacias leiteiras do Estado, com destaque para a região Oeste, onde se concentram as principais indústrias e as propriedades leiteiras de produção mais intensiva, embora o presente estudo não tenha observado associação estatística entre a ocorrência da doença e a região geográfica em que os focos foram detectados.

Não foi encontrada associação estatística entre a ocorrência de tuberculose bovina e algumas variáveis que representam mecanismos compatíveis com a difusão do agente, com destaque para: aluguel de pasto, presença de pastagem em comum com outras propriedades, compartilhamento de água e bebedouros com outras propriedades, presença de animais silvestres de vida livre e existência de áreas de concentração de animais ou de pouso de boiadas em trânsito nas propriedades. Contudo, tal resultado pode ser reflexo das limitações do presente trabalho, decorrentes da baixa quantidade de focos observados. 0 reduzido número de casos positivos, segundo Dohoo, Martin \& Stryhn (2010), pode afetar a estimativa dos parâmetros e os testes estatísticos. Nas atuais condições epidemiológicas, recomenda-se que o sistema de vigilância da tuberculose bovina em Santa Catarina inclua a realização de estudos de caso-controle com o objetivo de caracterizar melhor os mecanismos de difusão da enfermidade, incluindo os fluxos e tipo de comércio de animais, e de estimar riscos relativos que retroalimentarão o planejamento das atividades de vigilância.

\section{CONCLUSÕES}

A prevalência estimada de focos e de fêmeas adultas positivas para tuberculose bovina foi baixa em todas as cinco regiões catarinenses e no Estado como um todo, não tendo sido observada diferença estatística entre as regiões. A análise de regressão logística indicou maior chance de ocorrência da tuberculose bovina em propriedades maiores e naquelas de atividade leiteira. Os resultados deste trabalho estão coerentes com os dos estudos realizados em outras regiões do país, indicando uma relação da doença com a atividade leiteira, tamanho de rebanho e nível de tecnificação das propriedades.

Os presentes resultados sugerem que as autoridades sanitárias do Estado priorizem a vigilância baseada em risco, voltada para bacias leiteiras de produção mais intensiva. É importante destacar que, para os níveis de prevalência encontrados, os estudos transversais apresentam limitações, sendo recomendadas abordagens metodológicas de tipo longitudinal para a identificação mais detalhada dos possíveis fatores de risco associados à ocorrência e difusão da tuberculose bovina em Santa Catarina.

\section{REFERÊNCIAS}

Belchior A.P.C. 2000. Prevalência, distribuição regional e fatores de risco da tuberculose bovina em Minas Gerais. Dissertação de Mestrado em Medicina Veterinária, Escola de Veterinária, Universidade Federal de Minas Gerais, Belo Horizonte, MG. 55p.

Brasil 2001. IN no 2, de 10 de janeiro - Aprova o Regulamento Técnico do Programa Nacional de Controle e Erradicação da Brucelose e Tuberculose Animal Ministério da Agricultura Pecuária e Abastecimento. $<$ www.agricultura.gov.br>. Acesso em 31 out 2014.

Brasil 2004. IN no 6, de 08 de janeiro - Aprova o Regulamento Técnico do Programa Nacional de Controle e Erradicação da Brucelose e Tuberculose Animal. Ministério da Agricultura Pecuária e Abastecimento. $<$ www.agricultura.gov.br>. Acesso em 31 out 2014.

Brasil 2006. Programa Nacional de Controle e Erradicação da Brucelose e da Tuberculose Animal (PNCEBT): Manual técnico. Ministério da Agricultura Pecuária e Abastecimento, Brasília, DF. 188p.

CRMV-PR, CRMV-SC \& CRMV-RS. 2009. Manual de Zoonoses. 1:142-161.

Costa L.B. 2012. Tuberculose bovina em regiões de relevância econômica no Estado da Bahia. Dissertação de Mestrado em Ciência Animal nos Trópicos, Escola de Medicina Veterinária e Zootecnia, Universidade Federal da Bahia, Salvador, BA. 121p.

Dohoo I., Martin W. \& Stryhn H. 2010. Veterinary Epidemiologic Research. $2^{\text {nd }}$ ed. University of Prince Edward Island, Charlottetown. 865p. 
Embrapa. 2012. Ranking da produção de leite por Estado, 2010/2011. Centro Nacional de Pesquisa de Gado de Leite. <http://www.cnpgl.embrapa.br/nova/informacoes/estatisticas/producao/tabela0240.php>. Acesso em 03 abr 2014.

Santa Catarina. 2014a. Geografia. Governo do Estado de Santa Catarina < http://www.sc.gov.br/index.php/geografia > Acesso em 12 dez 2014.

Santa Catarina. 2014b. Economia. Governo do Estado de Santa Catarina <http://www.sc.gov.br/index.php/ economia> Acesso em 12 dez 2014.

IBGE. 2014a. Estados@ - Santa Catarina: Síntese. <http://www.ibge.gov.br/estadosat/perfil.php?sigla=sc\#> Acesso em 11 dez 2014.

IBGE. 2014b. Indicadores IBGE: Estatística da produção pecuária - Dezembro de 2014. <http://www.ibge.gov.br /estadosat/perfil.php?sigla=sc\#> Acesso em $11 \mathrm{dez} 2014$.

IBGE. 2014c. Estados@ - Santa Catarina: Pecuária 2012. <http://www.ibge.gov.br/estadosat/temas. php?sigla=sc\&tema=pecuaria2012> Acesso em 11 dez 2014.

INPE. 2014. Climatologia de precipitação e temperatura. CPTEC/INPE. <http://climanalise.cptec.inpe.br / rclimanl/ boletim/cliesp10a/chuesp.html> Acesso em $12 \mathrm{dez} 2014$.

Livingstone P.G., Ryan T.J., Hancox N.G., Crews K.B., Bosson M.A.J., Knowles G.J.E. \& McCook W. 2006. Regionalisation: a strategy tha will assist with bovine tuberculosis control and facilitate trade. Veterinary Microbiology. 112:291-301.

Lôbo J.R. 2008. Análise custo-benefício da certificação de propriedades livres de tuberculose bovina. Dissertação de Mestrado em Agronegócios, Universidade de Brasília, Brasília, DF. 84p.

Néspoli J.M.B. 2012. Situação epidemiológica da tuberculose bovina no Estado de Mato Grosso. Dissertação de Mestrado em Ciências, Faculdade de Medicina Veterinária e Zootecnia, Universidade de São Paulo, São Paulo, SP. $44 \mathrm{f}$.

Neves B.M.C. 2014. Caracterização produtiva e aspectos sanitários relacionados à bovinocultura em Santa Catarina. Dissertação de Mestrado em Saúde Animal, Faculdade de Agronomia e Medicina Veterinária, Universidade de Brasília, Brasília, DF. 28p.

OIE. 2014. Listo f FMD free member countries (according to Resolution no $15-82^{\text {nd }}$ general session May 2014): FMD free zone where vaccination is not practiced <http://www.oie.int/en/animal-health-in-theworld/official-disease-status/fmd/list-of-fmd-free-members/> Acesso em $11 \mathrm{dez} 2014$.

Petrie A. \& Watson P. 2009. Estatística em ciência animal e veterinária. $2^{\text {nd }}$ ed. Roca, São Paulo. 236p.

Rothman K.J., Greenland S. \& Lash T.L. Modern Epidemiology. $3^{\text {rd }}$ ed. LIPPINCOTT WILLIAMS \& WILKINS, Philadelphia. $751 \mathrm{p}$.

Sergeant E.S.G. 2014. Epitools epidemiological calculators. AusVet Animal Health Services and Australian Biosecurity Cooperative Research Centre for Emerging Infectious Disease. <http://epitools.ausvet.com.au> Acesso em 22 mai 2014.

Silva M.C.P. 2012. Epidemiologia e fatores de risco da tuberculose bovina no Paraná. Tese de doutorado em Ciência Animal, Centro de Ciências Agrárias, Universidade Estadual de Londrina, Londrina, PR. 82f.

Skuce R.A., Allen A.R. \& McDowell, W.J. 2012. Herd-level risk factors for bovine tuberculosis: a literature review. Veterinay Medicine International. 2012:1-10.

STATA MP 12. 2014. Stata: Release 12. Data analysis and statistical software. College Station, TX: StataCorp LP. 